\title{
1 Anisotropic Shear Behavior of Closely Jointed Rock Masses
}

2

3 Bo LI $^{1)}$, Yujing JIANG ${ }^{1)}$, Tateru, MIZOKAMI ${ }^{2)}$, Kouji IKUSADA ${ }^{2)}$ and Yasuhiro 4 MITANI $^{3)}$

5

$6 \quad{ }^{1)}$ School of Engineering, Nagasaki University, Nagasaki 852-8521, Japan

$7 \quad{ }^{2)}$ Kyushu Electric Power Co., Inc., Fukuoka 815-8521, Japan

$8 \quad$ 3) School of Engineering, Kyushu University, Fukuoka 812-8581, Japan

9

10 Corresponding author:

11 Yujing Jiang, School of Engineering, Nagasaki University, Nagasaki 852-8521, Japan

12 Tel: +81-95-819-2612

$13 \quad$ Fax: +81-95-819-2627

14 Email address: jiang@civil.nagasaki-u.ac.jp 


\section{ABSTRACT:}

16 In this study, in-situ shear tests on a closely jointed rock mass containing two sets of joints, 17 one continuous and another staggered, were conducted. A series of laboratory shear tests with 18 varying combinations of loading conditions and geometrical characteristics of rock joints 19 were also carried out. A Discrete Element Method (DEM) was used to numerically simulate 20 the in-situ and laboratory shear tests. The in-situ tests, laboratory tests and numerical modeling were aimed at evaluating the anisotropic shear behavior of closely jointed rock masses. Comparison between the test and simulation results of this study with the results of similar laboratory tests was completed. The simulation results agreed well with the laboratory test results and provided slightly higher shear stresses comparing to the results of in-situ shear tests. The test and simulation results showed that the jointed rock masses exhibited strong anisotropic shear behavior, the significance of which depended on the orientation of continuous joint set. Different failure mechanisms were confirmed in the tested and simulated rock mass models with different geometrical characteristics of rock joints, which resulted in 29 the anisotropic shear behavior.

Keywords: Jointed rock mass; Shear behavior; Laboratory test; In-situ test; Numerical simulation; Anisotropy 


\section{INTRODUCTION}

The shear behavior of jointed rock masses is an important issue in rock engineering, especially for the stability of slopes and dam foundations. However, limited cases of in-situ shear tests have been conducted, mainly due to their high costs and technical challenges in implementation (e.g., [1]-[5]). The shear behavior of closely jointed rock masses is governed by the mechanical properties of intact rock matrix and mechanical and geometrical characteristics of rock joint systems, such as the orientations of the joint sets and direction of the shear loading. Different geometrical characteristics will induce different failure mechanisms of rock masses during shear processes, resulting in different shear behavior [6].

Since in-situ tests are expensive, laboratory tests are typically conducted to give insight into the deformation behavior and failure mechanisms of jointed rock masses subjected to unconfined compression (e.g., [7]), biaxial compression (e.g., [8]) and triaxial compression (e.g., [9]). Such laboratory test results show that the strength of a jointed rock mass increases with the increase of confining stress and decrease of joint density, decreasing to the lowest value at a critical joint orientation. Different failure modes, such as splitting and shearing through intact rock and sliding along rock joints, can be observed on the models with different geometrical characteristics of rock joints. Hayashi and Fujiwara [10] conducted a series of direct shear tests on jointed rock mass models with one continuous joint set and reported that higher shear strengths could be observed in most orientations of a positive joint orientation system than that in a negative joint orientation system (see Fig. 1). His results showed that the compaction of rock mass increased the normal stress acting on rock joints, resulting in the increase of the strength of rock mass in the positive joint orientation system, while the dilation of rock mass reduced the strength of negative joint orientation system. Kawamoto [11] conducted shear tests on similar mass models, and found that in the positive joint orientation 
system, cracking initiated in the position underneath the toe of the face of the loading block subjected to shear loading, which propagated and connected with pre-existing joints and finally formed the failure plane. In the negative joint orientation system, opening of joints firstly happened in the same position, which then induced tensile cracks accompanied by the rotation of the rock mass, leading to the ultimate failure (see Fig. 9 presented later). Nagayama et al. [12],[13] also conducted shear tests on jointed rock mass models, emphasizing on the influence of rock joint orientation on the shear strength of rock mass.

They reported that the strength of a jointed rock mass could be governed by the strength of intact rock, rock joints, or the mix of both depending on the orientation of the continuous joint set.

Besides the laboratory tests, numerical simulations using Discrete Element Method (DEM), which more realistically models the mechanical behavior (compression, sliding, opening etc.) and geometrical characteristics (orientation, gap, spacing etc.) of rock joints, have achieved tremendous success in helping understand the mechanical behavior of jointed rock masses [14]. Although jointed rock masses subjected to unconfined, biaxial, and triaxial normal compressions have been modeled in numerical simulations, no attention has been paid to modeling jointed rock masses subjected to the combined normal and shear loadings. In addition, many numerical studies lacked support from measured data from laboratory tests or in-situ tests, thus caused difficulties for justifications of validity and applicability of the numerical models.

To overcome the above mentioned shortcomings, combined research of numerical simulations and in-situ shear tests on a closely jointed rock mass, supported further by a series of laboratory shear tests, were conducted. Laboratory test models containing a set of continuous joints intersected by a set of staggered joints orthogonal to the continuous joint set were reproduced at a 1/3 scale using artificial rock materials. A series of shear tests on these 
laboratory test models were carried out, taking into account the influence of loading conditions (lateral restraint stress and initial normal stress) and the geometrical characteristics of the rock joints (dip angle and spacing), in order to investigate the anisotropic shear behavior of closely jointed rock masses. The mechanical properties of the in-situ intact rock and rock joints, and the artificial rock materials and joints for laboratory tests were measured through a well-planed laboratory testing procedure, which were then adopted in the numerical simulations of the shear tests using a DEM. The influence of the orientation of continuous joint set on the anisotropic shear behavior of rock masses was further studied with numerical models containing varying dip angles of the continuous joint set. The test and simulation results were verified through comparisons with the results of similar laboratory tests reported in literature.

\section{SETUP OF IN-SITU AND LABORATORY SHEAR TESTS}

\subsection{Characteristics of the prototype rock mass}

The site for the in-situ shear tests is located on Kyushu Island, Japan (a possible site for a foundation of a nuclear power plant). The rock mass in this site is constituted by Mesozoic clay slate, sandstone, and conglomerate, covered by a shallow layer of Cenozoic igneous rock. The rock mass is slightly weathered, and closely jointed by three sets of rock joints. The geometrical characteristics of rock joints and the mechanical properties of intact rocks and rock joints at two locations in this site with different rock types (location A: clay slate; location B: conglomerate) were investigated. The rock mass at location A was chosen as the prototype rock mass for the laboratory tests, and in-situ shear tests were conducted at location B. From a cross-sectional view, two sets of joints can be identified in the field, orthogonal to each other with different spacing. The joints of Set 1 are continuous with good persistence, 
are oriented perpendicular to the joints of Set 1. Fig. 2 shows an example of the core specimen sketch, the statistical orientation distribution of the rock joints and a cross-sectional view of the distribution of joints in the field. The sketches show a set of sub-vertical persistent rock joints (Set 1), intersecting with several parallel sub-horizontal rock joints (Set 2). The lower hemisphere stereographic projection of joint poles shows that most of the rock joints of Set 1 in the field have moderate to steep dip angles ranging from $50^{\circ}$ to $90^{\circ}$. Through the analysis of 34 boreholes with a maximum length of $230 \mathrm{~m}$ and field investigation by trench and tunnel excavations (Fig. 2c), the approximate cross-sectional profiles of the geometrical distribution of joints for the two locations were then obtained, as shown in Fig. 3.

According to the survey results, the spacing of Set 1 is $30 \mathrm{~mm}$ to $60 \mathrm{~mm}$, and that of Set 2 is $90 \mathrm{~mm}$ to $180 \mathrm{~mm}$ at location A. The mean spacing of joints of Set 1 is $50 \mathrm{~mm}$ with a standard deviation of $30 \mathrm{~mm}$, and $100 \mathrm{~mm}$ with a standard deviation of $60 \mathrm{~mm}$ for Set 2, at location B. Set 1 dips at mean angles of $70^{\circ}$ and $75^{\circ}$ at the locations $A$ and $B$, with standard deviations of $9.9^{\circ}$ and $8.2^{\circ}$, respectively.

Note that there is a third set of joints on the site with orientation normal to both set 1 and set 2 and in the out-of-plane direction in Fig. 2, which has a mean spacing larger than $1 \mathrm{~m}$. Its influence on the in-situ shear tests with a sheared area of $600 \mathrm{~mm} \times 600 \mathrm{~mm}$ is therefore negligible. This information also made a 2D numerical model for the site a reasonable simplification.

The physico-mechanical properties of the intact rocks and the mechanical properties of rock joints in the two locations are shown in Tables 1 and 2, respectively. The properties of intact rocks were estimated through standard laboratory unconfined compression tests and triaxial compression tests, and the properties of rock joints were estimated through laboratory direct shear tests. Core specimens were used for all tests. A servo-controlled direct shear apparatus was used in this study to accurately estimate the shear behavior of relevant rock 
joints, which is important since the deformation and failure of rock joints govern the total performance of the jointed rock masses. The testing procedure and some results are presented in detail in [15],[16].

\subsection{In-situ shear test}

The setup of the in-situ shear test conducted in location B followed the suggested method for determining shear strength of rock masses [17], and therefore, only a few important settings are summarized here. The area of the shear plane is $600 \mathrm{~mm} \times 600 \mathrm{~mm}$ and the height of the loading concrete block is $300 \mathrm{~mm}$. The direction of shear load was inclined $15^{\circ}$ with respect to the horizontal plane, and the increment of shear load at each loading step is 0.02 $\mathrm{MN}$ at a loading rate of $0.25 \mathrm{MPa} / \mathrm{min}$. Four LVDTs were installed on the top surface of the loading block (block subjected to normal and shear loads positioned above rock mass, see Fig. 4) and another four were installed on the back surface. The mean values of LVDTs on the top surface were taken for calculating the representative normal displacement and the mean values of those on the back surface were taken for calculating the representative shear displacement. Two cases of in-situ tests, numbered as case I-15-1 and I-15-2, were conducted with normal stresses of 0.4 MPa for case I-15-1 and 1.2 MPa for case I-15-2.

\subsection{Laboratory experiment}

(a) Testing apparatus

To reproduce the stress state and boundary conditions of the rock mass subjected to the in-situ shear test, 1/3 down-scaled physical test models were established by using a laboratory direct shear testing apparatus, as shown in Fig. 4. A series of shear tests were conducted by using this apparatus and some results have been reported in [18],[19], which were also included in this article. The test model has a length of $900 \mathrm{~mm}$, a height of $300 \mathrm{~mm}$ and a thickness of $100 \mathrm{~mm}$, and the loading block has a length of $200 \mathrm{~mm}$, a height of $100 \mathrm{~mm}$ and 
a thickness of $100 \mathrm{~mm}$, where the thickness stands for the dimension in the direction perpendicular to the $x-y$ plane. The capacity of jacks is $50 \mathrm{kN}$ for shear loading, $20 \mathrm{kN}$ for normal loading, and $50 \mathrm{kN}$ for lateral restraint. The shear load acting on the front face of the loading block is inclined by an angle of $15^{\circ}$ with respect to the horizontal plane, in order to suppress the rotation of the loading block during the test, as commonly adopted in the in-situ shear tests. The lateral restraint jacks provide stresses on the lateral boundaries for reproducing the initial in-situ stresses exerted by the surrounding rock mass. The faces of the test model parallel to the $x-y$ plane are free to move. Four LVDTs were installed on the top face of the loading block (two of them can be observed in Fig. 4) to measure the normal displacement, while another two LVDTs were installed on the back face of the loading block to measure the lateral (shear) displacement.

(b) Specimen of artificial rock mass

The artificial rock masses were constituted by a large number of small-sized blocks (see Fig. 4b), manufactured by using the mixture of plaster, slaked lime, standard sand and water with a weight ratio of 1:1:5:1.6, cured for 28 days. These blocks have two kinds of dimensions: the first kind has a width of $20 \mathrm{~mm}$, a length of $60 \mathrm{~mm}$, and a thickness of 100 $\mathrm{mm}$, and the second kind has a width of $10 \mathrm{~mm}$, a length of $30 \mathrm{~mm}$, and a thickness of 100 mm (1/3 of the rock blocks at the location A as shown in Fig. 3). Here, the width stands for the spacing of joints of Set 1, the length stands for the spacing of joints of Set 2, and the thickness stands for the dimension of the rock blocks in the direction perpendicular to the $x-y$ plane (see Fig. 3). By inclining the rock blocks to the required dip angle, the block collection then approximately reproduced the joint distribution in the in-situ rock mass of location A with a 1/3 down-scaling. The physico-mechanical properties of the rock-like test material and the mechanical properties of artificial rock joints are shown in Tables 1 and 2, respectively. 
These properties were estimated using the same methods for determining the properties of natural rocks at locations A and B (also shown in Tables 1 and 2). The shear stress-shear displacement relations of the artificial joints subjected to different normal stresses are shown in Fig. 5. Since the joints had planar and smooth surfaces, their cohesions and dilation angles (confirmed on normal displacement-shear displacement curves) were assumed to be 0 , and no obvious peak shear stress could be observed in these curves. The friction angle was estimated through the linear regression of the shear stress-normal stress curves, and the shear stiffness was estimated through the linear regression of the curves shown in Fig. 5, using the inclined portions. The normal stiffness of joints, which is a function of normal stress, was estimated from the normal stress-normal displacement curves obtained from the third or fourth cycle of the loading-unloading test using the Bandis model [20], with the deformation contributed by the intact rock cancelled. The estimated initial normal stiffness $k_{n i}$ is $7.56 \mathrm{GPa} / \mathrm{m}$ and the maximum joint closure $V_{m}$ is $0.03 \mathrm{~mm}$. Taking the joint opening and compressive stresses as positive values, the normal stiffness $k_{n}$ at arbitrary normal stress $\sigma_{n}$ can then be determined by the following equation [20].

$$
k_{n}=k_{n i}\left(\frac{k_{n i} \cdot V_{m}-\sigma_{n}}{k_{n i} \cdot V_{m}}\right)^{2}
$$

\section{(c) Testing procedure and cases}

Artificial rock blocks were carefully packed into the steel frame of the testing apparatus (see Fig. 4) to form a physical rock mass model. The loading block, manufactured by using high strength plaster, was then firmly bonded to the top surface of the rock mass model by using epoxy resin. By doing so, neither failure of the loading block nor slip between the loading block and the rock mass model would happen during the tests. Failure would only 
happen within the rock mass models. The lateral confining stress was firstly applied on a rock mass model, followed by the normal stress being applied on the loading block, in order to consolidate the model. Then, the shear stress was incrementally applied on the loading block until failure occurred, with a shear load of $0.98 \mathrm{kN}$ for each step and a loading rate of 0.49 $\mathrm{MPa} / \mathrm{min}$.

In-situ geological survey indicated that the continuous joint set (Set 1) in the field dips in a range of $50^{\circ}$ to $90^{\circ}$. To investigate its influence on the shear behavior of the test models, rock mass models of 5 different dip angles $\left(\theta=50^{\circ}, 70^{\circ}, 90^{\circ},-70^{\circ}\right.$ and $\left.-50^{\circ}\right)$ of Set 1 were constructed and tested. Here, joints rotating clockwise from the vertical axis ( $\left.\theta=90^{\circ}\right)$ up to $90^{\circ}$ were assigned a positive dip angle, and vice versa. Besides the dip angles, 2 kinds of block sizes $(10 \mathrm{~mm} \times 30 \mathrm{~mm}$ and $20 \mathrm{~mm} \times 60 \mathrm{~mm}, 1 / 3$ of those shown in Fig. 3a), which were the lower and upper bounds of the block sizes discovered in the field, were used in the model constructions. For loading conditions, 5 magnitudes of normal stresses (0.082 MPa, 0.2 MPa, 0.29 MPa, 0.49 MPa and 0.98 MPa) and 3 magnitudes of lateral restraint stresses (0.082 MPa, $0.16 \mathrm{MPa}$ and $0.33 \mathrm{MPa}$ ) were selected for the tests. These conditions then led to 14 rock mass models with different geometrical characteristics of joints as demonstrated in Fig. 6, and 36 testing cases in total as summarized in Table 3. As shown in Fig. 6, Model 1 is intact rock (without joints), Models 2-7 and 12-14 have the larger blocks (20 mm×60 mm), Models 8 and 9 have the smaller blocks (10 mm×30 mm), and Models 10 and 11 have the mixture of both. Offset of staggered joints in Models 2 and 3 were modified to create a few new models (Models 4 and 6 based on Model 2, and Models 5 and 7 based on Model 3) with identical density of joints but different geometrical distributions of the joints of Set 2. In the labeling of the test cases, such as case E-1-1, "E" is the capital letter of experiment, the first number stands for the model (from 1 to 14) used in this case, and the second number stands for the case number of the model, since several cases with different boundary conditions may be 
conducted on one model.

\section{NUMERICAL SIMULATIONS OF LABORATORY AND IN-SITU SHEAR TESTS}

The laboratory and in-situ shear tests were numerically modeled using the DEM code UDEC [21], utilizing the original values of the dimensions, mechanical properties and boundary conditions etc. of the laboratory and in-situ tests (see Fig. 6). The dimensions of the numerical models for in-situ tests are full scale (i.e., 3 times the size of the laboratory test models), and the properties of intact rock and rock joints of location B were adopted. Roller boundaries were applied to lateral and bottom boundaries (no lateral restraint stress). In the numerical models for laboratory tests, roller boundaries were applied to the right and bottom boundaries, and lateral restraint stress was applied on the left boundary as shown in Fig. 6 . 
models) were applied to mimic the in-situ stresses in the models. After reaching equilibrium, the shear load was then applied step by step until the ratio of incremental shear stress $\Delta \tau$ to incremental shear displacement $\Delta u, \Delta \tau / \Delta u$, reached $200 \mathrm{MPa} / \mathrm{m}$ for the models with positive dip angles, and $50 \mathrm{MPa} / \mathrm{m}$ for the models with negative dip angles, according to the experimental results. For the simulation of the in-situ test, the shear load was applied until the shear displacement reached $30 \mathrm{~mm}$. Since the numerical models are 2-D, the normal displacement was monitored at 2 points on the top surface of the loading block, and the shear displacement was also monitored at 2 points on the back face of the loading block.

18 selected experimental cases (see Table 3), 2 in-situ test cases, and 3 other test cases based on the in-situ test model by changing the dip angle of joints of Set 1 from negative to positive (S-16-1 \& S-16-2) and a model with randomly generated joints but keeping the other conditions unchanged (S-17-1) were simulated. Cases S-16-1 \& S16-2 aimed at comparing the behavior of rock masses with joint sets of positive or negative dip angles in order to assess anisotropic shear behavior. The numerical model of case S-17-1 was created by randomly generating joints based on the mean $\left(75^{\circ}\right)$ and deviation $\left(8.2^{\circ}\right)$ of dip angles of joints of Set 1 at location B. This model was used to represent the irregularly distributed rock joints in the field (see Fig. 2c) and to compare with the behavior of the models with regularly-spaced joints (e.g., S-15, see Fig. 6). For the label of cases in the context, "E” stands for laboratory experiment, "I" stands for in-situ test and "S" stands for their simulation cases.

\section{SHEAR TEST AND NUMERICAL SIMULATION RESULTS}

\subsection{In-situ shear test}

Shear stress-shear displacement and normal displacement-shear displacement curves obtained from in-situ shear tests and their numerical simulations are shown in Fig. 7. Cases S-16-1 \& S-16-2 have the magnitude of shear stresses 2-3 times higher than that of cases 

did not reach the ultimate failure and were terminated when their shear displacement reached $30 \mathrm{~mm}$. The shear stresses obtained from in-situ tests increase fast in the initial stage of shear (i.e., shear displacement less than $10 \mathrm{~mm}$ ), then keep almost constant values in the rest of shear. Shear stresses of cases S-15-1 \& S-15-2 are close to the test results during the initial stage of shear, which continuously increase in a linear manner and exceed the curves of test results at around $10 \mathrm{~mm}$ of shear displacement for the case S-15-1 and around $15 \mathrm{~mm}$ for the case S-15-2. In the numerical simulations, no failure of intact rock was identified during the shear process due to the large values of the strength parameters (i.e., cohesion and internal friction angle, see Table 1) adopted, which is not the case in the in-situ test where a failure plane underneath the loading block induced by cracking of intact rock was visually confirmed by removing the loading block after test. These differences between test and simulation showed an overestimated intact rock strength by numerical simulations that adopted the measured mechanical properties using small-sized intact rock samples. As a heterogeneous material in reality, there are always defects existing in the intact rock matrices, which may lead to reduction of the strength and elastic modulus of rock matrices. In laboratory tests, this phenomenon can, in some degrees, be avoided using artificial rock mass models. This issue will be discussed further in the simulations of laboratory tests.

Randomly generated rock joints were introduced into model 17 (see Fig. 6) based on the mean and deviation of the dip angle of the Set 1 . This model provided slightly closer shear stress-shear displacement curves to the test results than the model of regularly spaced joints (Model 15, see Fig. 6). The randomly jointed model had an assembly of rock blocks with different sizes and shapes, which provided more opportunities for the onset of sliding or separation of rock joints. It may serve as an alternative in simulating natural jointed rock masses, with known mean and deviation of the geometrical properties of rock joints. The 
normal displacement-shear displacement curves of simulations agree well with the test results. Model 16 has larger dilation than Models 15 \& 17.

In summary, lacking of failure and cracking processes in the intact rock in the numerical models resulted in overestimated shear strength of the in-situ rock mass, which requires more flexible treatments of the geometry of rock joints, such as introducing the random models, and implementation of in-situ large-scale triaxial compression tests to obtain more realistic mechanical properties of the rock mass, to take into account the influence of possible defects in the intact rock blocks.

\subsection{Laboratory shear tests}

(a) General behavior of jointed rock masses during shear

The results of normal stresses, shear stresses, normal displacements, and shear displacements of all laboratory tests and numerical simulation cases at failure are tabulated in Table 3. The normal stresses at failure are larger than their initial magnitudes because of the inclined shear loading direction ( $15^{\circ}$ with respect to the horizontal reference plane). Fig. 8 shows the comparisons between the relations of shear stress-shear displacement and normal displacement-shear displacement from test and simulation cases 1-3, 2-1, 2-3, 2-4, 3-1, 3-3 and 3-4, as a supplement to Table 3 showing only the final results at failure. The comparison illustrates the full stress-deformation paths from the start of loading until failure. Generally, higher shear stresses at failure can be expected in the cases with either larger initial normal stress (comparing between cases 2-1 to 2-5, or between cases 3-1 to 3-5), or smaller density of joints (comparing between Models 2 \& 8, or between Models 3 \& 9), with the positive dip angle of joints of Set 1 rather than the negative dip angle (comparing between Models 2 \& 3, or between Models 13 \& 14). The correlation coefficients between test and simulation results are tabulated at the last row in Table 3. The numerical simulation results of the normal and 
shear stresses match fairly well with the test results (correlation coefficients of 0.99 and 0.98 , respectively), while the results of the normal and shear displacements are poorly fitted against the measured data (correlation coefficients of 0.15 and 0.39 , respectively). These discrepancies are mainly due to the inevitable limitations of measurement sensor resolutions and possible errors, heterogeneity of or defects in the artificial materials, and/or the simplifications made for numerical models especially without cracking. In the tests, the displacements at peak shear stresses were significantly influenced by the small blocks with irregular shapes cut by the shear plane (see Fig. 6). The behavior of them was difficult to be reproduced in numerical models, since blind prediction for such randomly occurring small scale failure is difficult and may not affect the general trend of prediction results for the shear behavior, especially the strength behavior of the model.

As shown in Figs. 8a \& c, the test model with an intact rock mass containing no rock joints (Model 1) has higher peak shear stress and shear stiffness than the jointed models (Models 2 \& 3) under the same boundary conditions. The peak shear stress of Model 2 is around 3 times that of Model 3, exhibiting a strong anisotropic shear behavior. The shear stress of Model 1 increases linearly with the increase of shear displacement, reaching the peak shear stress at a shear displacement less than $1 \mathrm{~mm}$, which is similar to the shear behavior of an intact rock block or other brittle materials. By contrast, results of Models 2 \& 3 show yielding points where shear stiffness undergone significant drops, with their peak shear stresses occurring at shear displacements of 1.3-2.3 mm. As shown in Figs. 8b \& d, while Model 1 has almost 0 normal displacement during shear, dilations occur for Models 2 \& 3 in different magnitudes. Model 2 shows more contraction before turning into dilation than Model 3, while Model 3 shows little contraction but strong dilation during shear. Other models behave similarly with Models 2 \& 3, differing in the stress-displacement curves in different degrees subjected to changing boundary conditions and/or with different joint geometries. 
(b) Failure phenomena in the rock mass during shear

Intact rocks, as a sort of brittle solid materials, undergo cracking subjected to a loading process until failure, which, combined with the movements (separation, rotation and sliding) on pre-existing rock joints, serves as the principal source of macro-failure of a rock mass. The sketches of the cracking process in the cases E-2-1 \& E-3-1 at various shear stresses observed during shear tests are demonstrated in Fig. 9, as an example providing insight into the failure mechanisms of rock masses subjected to normal and shear stresses. In the case of E-2-1, cracks initiated underneath the back toe of the loading block (Fig. 9b), propagating along the orientation of joints of Set 2, towards the boundary at the right-hand side of the model. As the shear stress increased, more cracks were generated underneath the loading block (Fig. 9c), which connected with the pre-existing rock joints, forming a failure plane on which the upper structure could slide after failure (Fig. 9d). In the case of E-3-1, sub-horizontal cracks initiated several centimeters underneath the back toe of the loading block, accompanied by the opening of the joints of Set 1 underneath the front toe of the loading block (Fig. 9f). These were induced by the combined movements of the dilation and lateral compression of the rock blocks on the right hand side of the opened joints. The cracks underneath the back toe of the loading block gradually propagated towards the front side, connection and coalescence of which with pre-existing rock joints finally formed the failure plane (Fig. 9h). Note that only major cracks that could be visualized were demonstrated in these sketches, and there were much more micro-cracks occurring in the test models. Obviously, cracking of intact rock blocks took place in a wider range in the Model 2 than that in Model 3, and the failure plane in Model 2 was located in a deeper position than that of Model 3. This gave the reason of the results shown in Table 3 and Fig. 8, where Model 2 exhibited larger shear stress at failure than that of Model 3, because more energy (stress) was required to generate more new cracks 
spreading in a larger area in the model. Again, opening of joints happened in Model 3 due to the rotation of rock blocks on the right hand side of the opened joints, resulting in a more ductile shear behavior than that of Model 2 (Figs. 8a \& c), thus producing abundant dilation (Fig. 8d). The numerical code used in this study only takes into account the plastic flow of intact rock after failure without cracking process, which may also contribute to the differences observed between the test and simulation results.

\section{(c) Shear strength}

The relations between the peak shear stress and normal stress at failure of Models 1,2 \& 3 are shown in Fig. 10, by using the results of cases $1-1$ to $1-3,2-1$ to $2-5$ and $3-1$ to $3-5$ in Table 3, respectively, together with the failure envelops of the artificial intact rock and rock joints. Plots of Model 1 in the figure overlap with the failure envelop of the intact rock, which was obtained from the triaxial compression tests conducted on much smaller samples of the intact rock. This is a valuable evidence for verifying the reliability of mechanical properties used in the numerical simulations. The estimated cohesion and internal friction angles are also shown in Fig. 10, where cohesions of Model 2 and Model 3 are $0.77 \mathrm{MPa}$ and $0.31 \mathrm{MPa}$, respectively, and their internal friction angles are $44^{\circ}$ and $26^{\circ}$, respectively. These test results agree well with those of the simulation results. In the initial normal stress ranging $0.5-1.0$ MPa, the shear strength of Model 3 is about $50 \%$ of that of Model 2, which is about $80-90 \%$ of that of Model 1, revealing that a jointed rock mass with large positive dip angle of continuous rock joints (e.g., Model 2 in this study) may not undergo significant decrease of shear strength comparing to an intact rock body, due mainly to the interlocking effect of rock joints. Model 3, however, has a weak interlocking effect and exhibits shear strength just slightly above that of the rock joints.

(d) Mechanism of anisotropic shear behavior 
Test and simulation results of Models 2 \& 3 demonstrate anisotropic shear behavior of the jointed rock mass. Differences in shear strength, shear stiffness and dilation were found to be due to the previously mentioned interlocking effect. This effect can be relatively weak (e.g., Model 3) or strong (e.g., Model 2), depending on the stress state in the rock mass and the geometrical characteristics of rock joints. Again, take the Models $2 \& 3$ as examples, the forces acting on the shear plane can be schematically represented as shown in Fig. 11. At here, $N$ is the normal load and $S$ is the shear load acting on the loading block, $F$ is the resultant

force, and $F_{n}$ is the force normal to and $F_{s}$ is the force parallel with the orientation of joints of Set 1. With the increase of $S$ during shear, the orientation of $F$ will gradually rotate counterclockwise from vertical downward to the orientation demonstrated in Fig. 11, where $S=N$. At this state, in Model 2, $F_{n}(=1.4 S)$ exerts compression and $F_{S}(=0.8 S)$ exerts shear stresses on the joints of Set 1 towards the downward direction. The combination of these forces inhibit sliding of the joints of Set 1 as well as the dilation of the rock mass, while enhancing the confinement of the jointed rock mass. $F_{s}$ can turn to upward direction by continuously increasing the shear force up to $S>10.8 N$, which usually does not occur in a shear test. By contrast, in Model 3, when $S$ becomes larger than $0.4 N, F_{n}$ will contribute to the rotation of the rock mass in the clockwise direction, inducing opening of joints of Set 1 underneath the front toe of loading block (see Fig. 9). It will facilitate the sliding along surfaces of the joints of Set 1 since $F_{n}$ is smaller than $F_{s}$, accompanied by remarkable dilation. The failure of Model 2 is likely to be induced by the yielding of intact rock blocks underneath the shear plane subjected to high compression and shear stresses, similar to the failure of an intact rock during a triaxial test. The failure of Model 3 is likely to be induced by the tensile failure in the rock mass underneath the shear plane, along with the rotation/bending of rock mass. 
In summary, the anisotropic shear behavior of jointed rock masses with large dip angles (i.e., $50^{\circ}-90^{\circ}$ ) of continuous joint set originates from the different stress states of the continuous joint set during a shear. The shear strength can be strong in the condition that the normal stresses acting on the continuous joint set help inhibit the movements (sliding, opening \& rotation) along them, or can be weak in the opposite conditions, depending on the geometrical characteristics of rock joints.

(e) Influences of joint density, lateral restraint stress and configuration of the joints of Set 2

The shear test results of cases E-2-1 \& E-3-1 with rock block dimension of $20 \mathrm{~mm} \times 60 \mathrm{~mm}$, cases E-8-1 \& E-9-1 with rock block dimension of $10 \mathrm{~mm} \times 30 \mathrm{~mm}$ and cases E-10-1 \& E-11-1 with mixed rock block dimensions of both, under the same initial normal stress, are shown in the joints of Set 1, show that the shear stiffness increases with the decrease of joint density. However, their shear stresses at failure do not have obvious differences. By contrast, in the cases of E-3-1, E-9-1 \& E-11-1, both of the shear stiffness and shear stresses at failure increase with the decrease of joint density. Comparing with the failure mechanism and the shear strength of Model 2, it seems that the shear strength of the models with large positive dip angles of the continuous joint set like Model 2 is not sensitive to the density of rock joints, since they have already achieved the shear strength as high as $80-90 \%$ of that of the intact rock. The shear strengths, shear stiffness and dilations of the models with large negative dip angle of the continuous joint set, like Model 3, increase proportionally with the decrease of joint density. However, due to the limited testing cases, more in-depth mathematical descriptions about their relations have not been reached in this study.

$$
\text { As presented in Table 3, comparisons of cases E-2-1, E-2-6 \& E-2-7, and cases E-3-1, }
$$
E-3-6 \& E-3-7 show that the lateral restraint stress has limited influence on the shear strength 
of jointed rock mass. Comparisons of cases E-2-1, E-4-1 \& E-6-1, and cases E-3-1, E-5-1 \& E-7-1 show that the influence of the configuration of the joints of Set 2 with different offsets on the shear strength of jointed rock mass is also negligible. Note that in these models, the dip angle of the joints of Set 1 is either $70^{\circ}$ or $-70^{\circ}$, tested within a small range of lateral restraint stress with slight changes on the configuration of the joints of Set 2. The shear behavior of these models may change if these parameters are modified in larger ranges, which, however, is beyond the focus of this study.

\subsection{Simulation cases and results}


The simulation results of all cases at failure are presented in Table 4, and the shear

stress-shear displacement and normal displacement-shear displacement curves of the modeling cases with initial normal stress of $0.39 \mathrm{MPa}$ are shown in Fig. 13. The shear stress increases proportionally with the increase of shear displacement for the case with $\theta=90^{\circ}$, reaching the ultimate failure directly after the appearance of yielding point (see Fig. 13a), exhibiting typical failure behavior of brittle materials. The shear stresses of the cases with negative dip angles (see Fig. 13c) also increase in a linear manner with the increase of shear displacement until the yielding points, followed by a short strain-softening stage to reach the ultimate failure. For the cases with positive dip angles, the yielding points appear at the early stage of the whole shear processes, for instance, at $0.4 \mathrm{~mm}$ for $\theta=30^{\circ}$ and at $7 \mathrm{~mm}$ for $\theta=70^{\circ}$, followed by a long gradual yielding stage until the ultimate failure occurred (see Fig. 13a). For most of the cases, the yielding points appear at the shear displacements where maximum contractions (maximum negative normal displacements) appear, revealing that the turning point of contraction to dilation of a rock mass during a shear process has inherent connection with the appearance of the yielding point, which can also be observed in the laboratory shear test results (see Fig. 8).

\subsection{Shear strength and failure mechanism}

Peak shear stress-normal stress relations of the cases $\theta= \pm 10^{\circ}, \pm 30^{\circ}, \pm 50^{\circ}, \pm 70^{\circ} \& 90^{\circ}$, together with the strength envelopes of intact rock and rock joints are shown in Fig. 14. The cases with positive dip angles have smaller shear strengths than that of the cases with negative dip angels in the range $\theta= \pm 10^{\circ}- \pm 30^{\circ}$. This relation is reversed in the range $\theta= \pm 40^{\circ}- \pm 80^{\circ}$. Cases $\theta=10^{\circ}, 30^{\circ},-50^{\circ} \&-70^{\circ}$ have very weak shear strength as low as the shear strength of the rock joints, while case $\theta=90^{\circ}$ has a shear strength close to that of the intact rock. The shear strength of the case $\theta=70^{\circ}$ is $70-80 \%$ of the intact rock, and the shear strength of the case $\theta=-70^{\circ}$ is 
around $10 \%$ above that of the rock joints, which have good agreements with the results of the laboratory shear test (see Table 3).

The failure mechanisms of the models with dip angles of the joints of Set 1 of $\pm 70^{\circ}$ has been thoroughly investigated and discussed in the last chapter by analyzing the forces acting on the joints of Set 1 in the models (see Fig. 11). By using the same method, one can analyze the state of forces acting on the joints of Set 1 in various models so as to investigate the deformation and failure mechanisms of the rock masses. Here, only a brief description about the failure mechanisms obtained from numerical simulations is presented below. Note that the shear strength mentioned below refer to the shear stress at failure under various normal stresses ranging from 0.5-2.5 MPa as shown in Fig. 14.

(a) Cases with positive dip angles of the joints of Set 1

For the cases of $\theta=10^{\circ}-30^{\circ}$, the failure is governed by the sliding (slip failure) of the joints of Set 1 underneath the loading block, leading to the shear strength of the rock mass models close to that of the rock joints. For the case of $\theta=40^{\circ}$, the failure firstly occurs in the intact rock, inducing progressive cracking gradually connecting to the joints of Set 1 . Then the sliding of the upper body mainly along the joints of Set 1 happens, producing a shear strength between that of the intact rock and the rock joints. For the cases of $\theta=50^{\circ}-80^{\circ}$, the failure is mainly governed by the cracking in the intact rock underneath the loading block, as depicted in Section 4.2(d), exhibiting strong shear strengths as high as $90 \%$ of that of the intact rock.

(b) Cases with negative dip angles of the joints of Set 1

For the cases of $\theta=-10^{\circ} \&-20^{\circ}$, the failure is mainly governed by the buckling failure of the rock blocks underneath the back toe of the loading block subjected to compression, since sliding of joints are extremely difficult in these cases. Models of these cases produce shear strength over $50 \%$ of that of the intact rock. For the cases of $\theta=-30^{\circ}$ to $-70^{\circ}$, tensile failure in 
the rock blocks underneath the loading block happens along with the rotation of the rock blocks, producing much weak shear strength close to that of the rock joints. For the case of $\theta=-80^{\circ}$, the rotation of rock blocks is inhibited due to the sub-vertical orientation of the joints of Set 1 . It can be categorized as the same group with the cases of $\theta=80^{\circ} \& 90^{\circ}$, where failure of rock mass is governed by the shearing failure in the intact rock underneath the loading block, therefore providing strong shear strength as high as $90 \%$ of that of the intact rock.

\subsection{Comparison with previous studies}

There are a series of data available in literature, regarding the laboratory shear tests on closely jointed rock masses with various dimensions, among which, four sets of data carried out by three different research groups have been selected, and were compared with the laboratory shear test and numerical simulation results obtained in this study, as shown in Fig. artificial jointed rock mass specimens with one set of joints dipping at different angles, where the dimension of Hayashi (1965) model is $30 \mathrm{~cm} \times 20 \mathrm{~cm} \times 10 \mathrm{~cm}$ with a joint spacing of $3 \mathrm{~cm}$, and the dimension of Nagayama (1994) model is $15 \mathrm{~cm} \times 15 \mathrm{~cm} \times 15 \mathrm{~cm}$ with a joint spacing of $1 \mathrm{~cm}$. Kawamoto [11] and Nagayama and Katahira [12] also conducted shear tests on artificial jointed rock mass specimens with one set of joints dipping at different angles, where the areas of shear plane and rock mass model for Kawamoto (1970) model are $10 \mathrm{~cm} \times 4 \mathrm{~cm}$ and 30 $\mathrm{cm} \times 4 \mathrm{~cm}$ respectively with a joint spacing of $1 \mathrm{~cm}$, and the areas of shear plane and rock mass model for Nagayama (1989) model are $20 \mathrm{~cm} \times 20 \mathrm{~cm}$ and $40 \mathrm{~cm} \times 40 \mathrm{~cm}$, respectively, with a joint spacing of $1 \mathrm{~cm}$. Since these tests adopted different testing methods by using models of various geometrical and mechanical properties, direct comparison of results with them would be difficult to comprehend and may lead to misunderstanding. As an alternative, for each dataset, the ratios of the shear strengths of the models with various dip angles to the 
model with dip angel of $90^{\circ}$ was calculated, leading to the normalized ratio $\tau_{\theta} / \tau_{90^{\circ}}$, which was used as the vertical coordinate in Fig. 15. Since these datasets have different ranges of normal stresses, the mean normal stress at failure of each dataset and its corresponding shear stress were calculated. In this frame of presentation, the normal stress corresponding to the shear strength shown in Fig.15 of laboratory model tests is $0.2 \mathrm{MPa}$, of numerical simulations is 1.0 MPa, of Hayashi (1965) model is $0.15 \mathrm{MPa}$, of Kawamoto (1970) model is $0.12 \mathrm{MPa}$, of Nagayama (1989) model is $0.89 \mathrm{MPa}$, and of Nagayama (1994) model is 0.44 MPa. Similar tendencies can be observed on these datasets obtained from shear tests or numerical much larger shear strength at $\theta=-45^{\circ}$ than other models. For the cases with positive dip angles, the shear strength monotonically increases with the increase of dip angle, in which the lowest strength can be found when $\theta=10^{\circ}-20^{\circ}$, and the maximum strength can be found when $\theta=60^{\circ}-90^{\circ}$. The cases with negative dip angles can have large shear strength either at small dip angles (e.g., $-20^{\circ}$ ) or at large dip angles (e.g., $-80^{\circ}$ ), and have the lowest strength when $\theta=-50^{\circ}$

$0.68,0.39,0.53,0.28,0.79,0.41,0.78,0.82,0.99,0.91,1.03,0.64,0.43,0.25,0.65,0.49$, 
compare the properties of an objective rock mass to these models to assess the anisotropic shear behavior, especially to help realize the weakest shearing orientation when stability assessment problems are encountered.

\section{CONCLUSIONS}

In this study, based on the in-situ measurement data, a closely jointed rock mass was reproduced in a series of 1/3 scale laboratory test models using artificial rock materials, and a number of laboratory shear tests and in-situ shear tests were conducted. Their numerical simulations were implemented by means of DEM models, the results of which were in good agreements with the test results in general. The influence of the orientation of the continuous joint set on the anisotropic shear behavior of closely jointed rock masses was also studied by means of a series of numerical models with various dip angles of the set of continuous joints, the results of which were compared with the results of similar laboratory tests in literature.

The good agreement of the results of laboratory shear tests adopting homogeneous rock-like material and their numerical simulations adopting Mohr-coulomb failure criterion suggests that proper estimations of the mechanical properties of intact rock and rock joints, and proper representation of the geometrical characteristics of rock joint systems are key issues for reliable numerical modeling of jointed rock masses. Special emphasis has to be placed on the mechanical properties of rock joints, which play a crucial role in the failure behavior of jointed rock masses. It requires a well-planed laboratory test procedure, especially with the employment of servo-controlled direct shear apparatus to estimate their properties. The numerical simulations of in-situ shear tests, however, slightly overestimated the shear strength, due mainly to the fact that comparing to the numerical models that adopted the mechanical properties measured on small-sized intact rock samples, the natural rock masses may contain various defects in the rock block matrices beside the rock joints, which could 
reduce the strength of the in-situ rock mass. This issue remains still one crucial difficulty in the estimation of the behavior of jointed rock masses through numerical approaches.

Closely jointed rock masses exhibit strong anisotropic shear behavior in terms of significant differences in shear strength and shear stiffness when sheared at different directions, the significance of which varies with the orientation of the sets of continuous joints. The results obtained from this research show non-linear relations between the shear strength and the orientation of the single set of continuous joints, due to the various failure mechanisms involved. The failure mechanism of jointed rock masses subjected to shear can be classified, in an order from high shear strength towards the low ones, by shearing within intact rock when $\theta=-80^{\circ} \& 50^{\circ}-90^{\circ}$, buckling of intact rock when $\theta=-10^{\circ}$ to $-20^{\circ}$, mixing of shearing and sliding when $\theta=40^{\circ}$, tensile failure in intact rock accompanied by rotation of rock blocks when $\theta=-30^{\circ}$ to $-70^{\circ}$, and sliding of rock joints when $\theta=10^{\circ}-30^{\circ}$. Besides the geometrical characteristics of rock joints, one may expect more significant anisotropy when the strength difference between intact rock and rock joints is greater. Such anisotropic behavior needs to be adequately assessed to reach a mathematical expression using, for instance, inclination parameter and joint factor to account for the effects of joints, and to include it in rock mass classification systems in the future studies.

\section{ACKNOWLEDGEMENTS}

The authors would like to express their appreciation to Dr. Lanru Jing at Royal Institute of Technology, Stockholm, Sweden for his help. This study has been partially funded by Kyushu Electric Power Co., Japan and Grant-in-Aid for Young Scientists (B) (No. 24760690), Japan. These supports are gratefully acknowledged.

\section{REFERENCE}

[1] Barla G, Robotti F, Vai L. Revisiting large size direct shear testing of rock mass 
613 foundations. In: Proc $6^{\text {th }}$ Int Conf Dam Eng, Lisbon, Portugal, 2011. pp.179-188.

614 [2] Coli N, Berry P, Boldini D. In situ non-conventional shear tests for the mechanical characterisation of a bimrock. Int J Rock Mech Min Sci 2011;48:95-102.

616 [3] Liu SH, Xiao GY, Yang JZ, Wu GY. Large-scale in-situ direct shear tests on rockfill 617 materials of upper reservoir dam in Yixing pumped storage power station. In: Proc $4^{\text {th }}$ Int 618 Conf Dam Eng, Nanjing, China, 2004. pp.545-550.

619 [4] Helgstedt MD, Douglas KJ, Mostyn G. A re-evaluation of in-situ direct shear tests, 620 Aviemore Dam, New Zealand. Australian Geomechanics 1997;31:56-65.

621 [5] Takano M, Furujo I. Deformation and resistance in in-situ block shear test on a black 622 schist and a characteristic loading pattern. In: $1^{\text {st }}$ Int Soc Rock Mech Cong, Lisbon, Portugal, 623 1966. pp.765-768.

624 [6] Hudson JA, Harrison JP. Engineering Rock Mechanics: An Introduction to the Principles, 625 Pergamon, Oxford, 1997.

626 [7] Singh M, Rao KS, Ramamurthy T. Strength and deformational behavior of a jointed rock 627 mass. Rock Mech Rock Eng 2002;35:45-64.

628 [8] Lama RD, Vutukuri VS. Handbook on mechanical properties of rocks. Testing techniques 629 and results, Volume 4, Trans Tech Publications 1978. 515p.

630 [9] Pomeroy CD, Hobbs DW, Mahmoud A. The effect of weakness-plane orientation on the 631 fracture of Barnsley Hards by triaxial compression. Int J Rock Mech Min Sci 1971; 632 8:227-238. [10] Hayashi M, Fujiwara G. Anisotropy of shear resistance and dilatancy of jointy mass and some mechanisms of fracture in direct shear. In: Proc $3^{\text {rd }}$ Japan Symp Rock Mech, 1965. pp.17-21. (In Japanese)

636 [11] Kawamoto T. Macroscopic shear failure of jointed and layered brittle media. In: Proc 2nd 637 Cong Int Soc Rock Mech, Belgrade, Serbia, 1970. 2:215-221. 
638 [12] Nagayama I, Katahira H. Shear test of gypsum modeling stratiform rock. Civil 639 Engineering Journal 1989;31:25-30. (In Japanese)

640 [13] Nagayama I, Norimatsu H, Katahira H, Ozawa Y, Morita S. Influences of dip and 641 shearing strength of joints on shearing strength of rock mass. In: Proc $9^{\text {th }}$ Japan Symp Rock

642

643

644 Mech, 1994. pp.391-396. (In Japanese)

[14] Jing L, Stephansson O. Fundamentals of discrete element methods for rock engineering. Elsevier Publishers, Oxford, UK 2007.

[15] Jiang Y, Xiao J, Tanabashi Y, Mizokami T. Development of an automated servo-controlled direct shear apparatus applying a constant normal stiffness condition. Int J Rock Mech Min Sci 2004;41:275-286.

[16] Jiang Y, Li B, Tanabashi Y. Estimating the relation between surface roughness and mechanical properties of rock joints. Int J Rock Mech Min Sci 2006;43:837-846.

[17] Brown ET (ed.). ISRM suggested methods. Pergamon Press, Oxford, 1981. 211p.

[18] Mizokami T, Mitani Y, Esaki T, Katsuki O. Experimental and numerical simulation of shear tests for rock masses with steeply dipped discontinuities. Doboku Gakkai Ronbunshuu C 2003;62:43-57. (In Japanese)

[19] Mizokami T, Ikusada K, Esaki T, Mitani Y. Physical and analytical simulation of in-situ shear test on steeply dipped rock masses. Rock Mechanics in the National Interest: Proc $38^{\text {th }}$ U.S. Rock Mech Symp, Washington, USA, 2001. 2:1445-1450.

[20] Bandis S, Lumsden AC, Barton NR. Fundamentals of rock joint information. Int J Rock Mech Min Sci Geomech Abstr 1983;20:249-268.

[21] Itasca Consulting Group, Inc. UDEC-Universial Distinct Element Code. Version 3.0, User Manual, Minnesota, USA, 1998.

[22] Mizokami T. Evaluation of shear behavior of jointed rock masses and mechanism of shear anisotropy. Ph. D thesis, Kyushu University, Fukuoka, Japan, 2003. (In Japanese) 


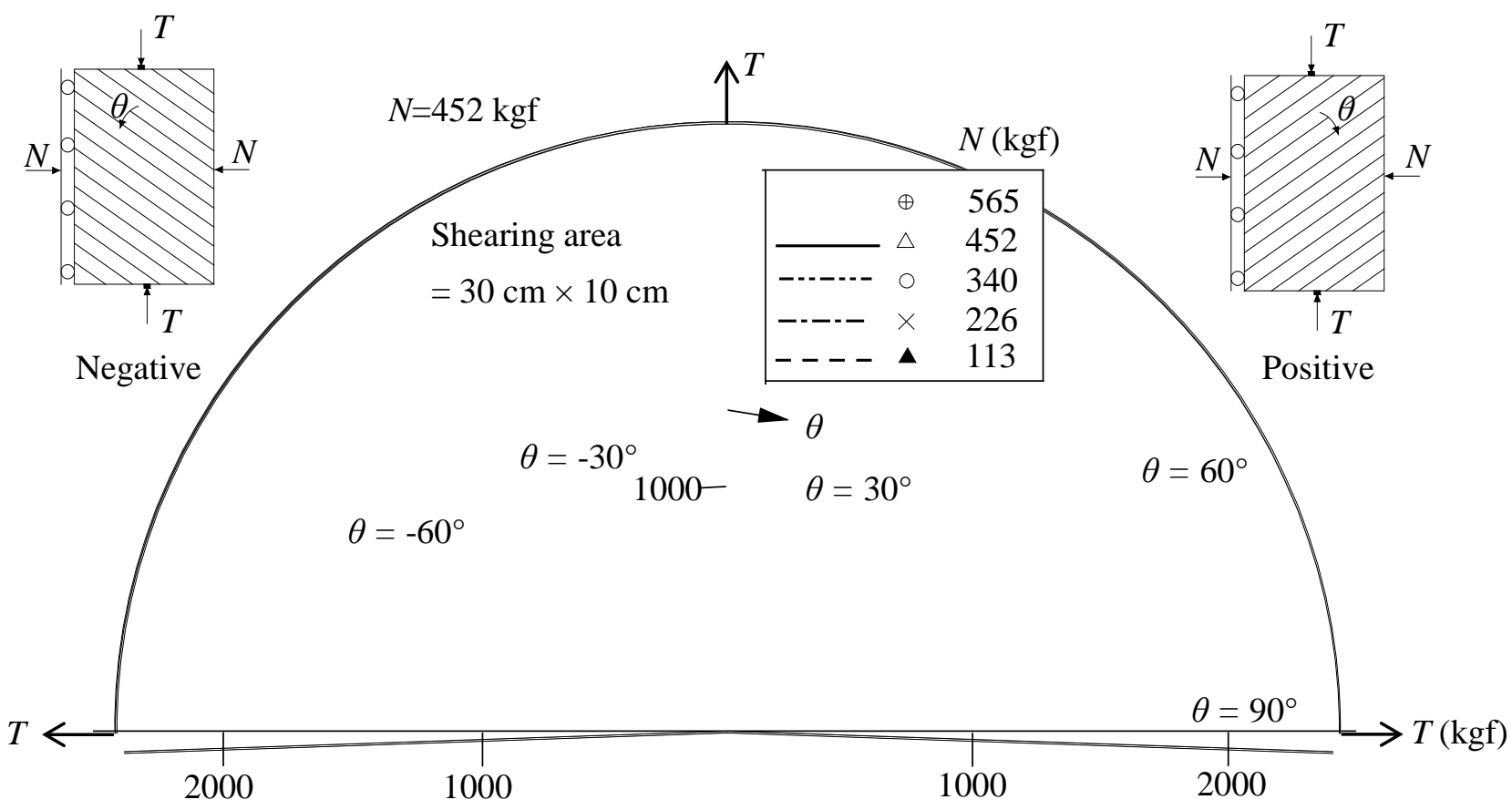

Figure 1. Results of shear tests conducted by Hayashi and Fujiwara [10] on jointed rock masses with positive and negative joint orientation systems. 

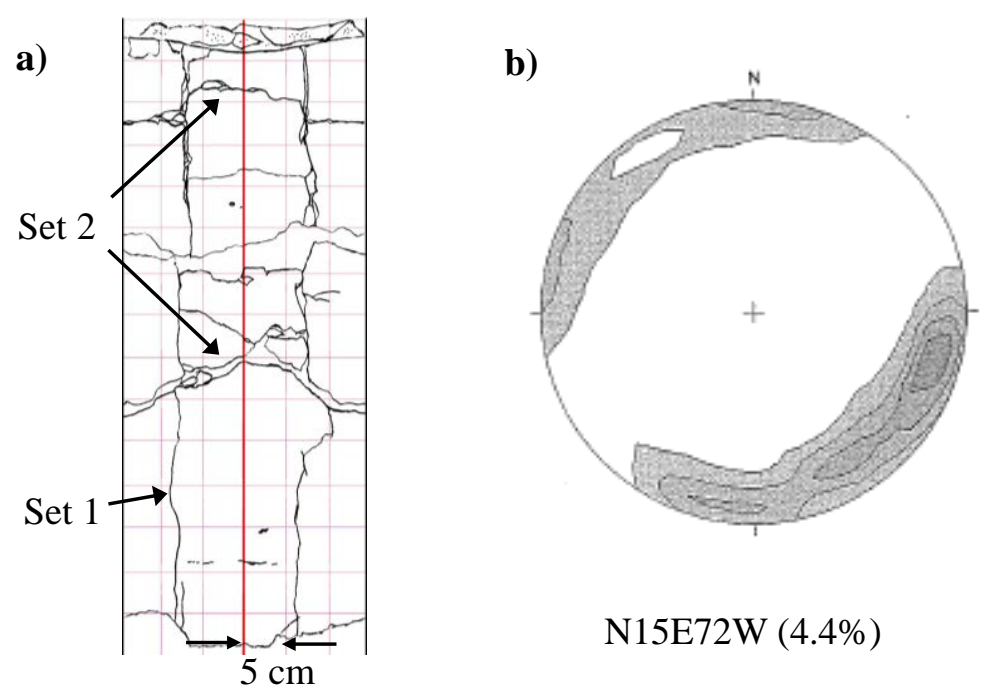

N15E72W (4.4\%)

Ground surface

c)

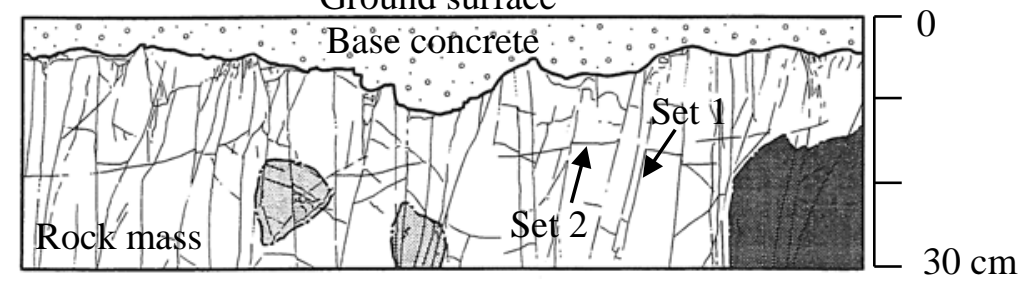

Figure 2. a) An example of borehole sketch of rock joints; b) Lower hemisphere stereographic projection of the orientation of continuous rock joints in the rock mass; c) A cross-sectional sketch of the geometrical distribution of rock joints at location A. 
a)

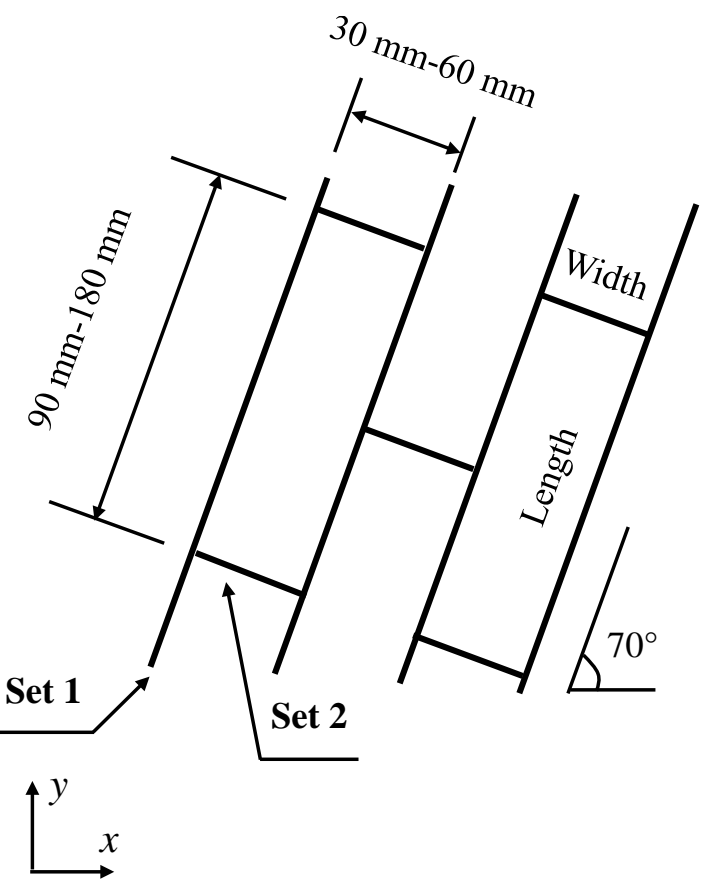

b)

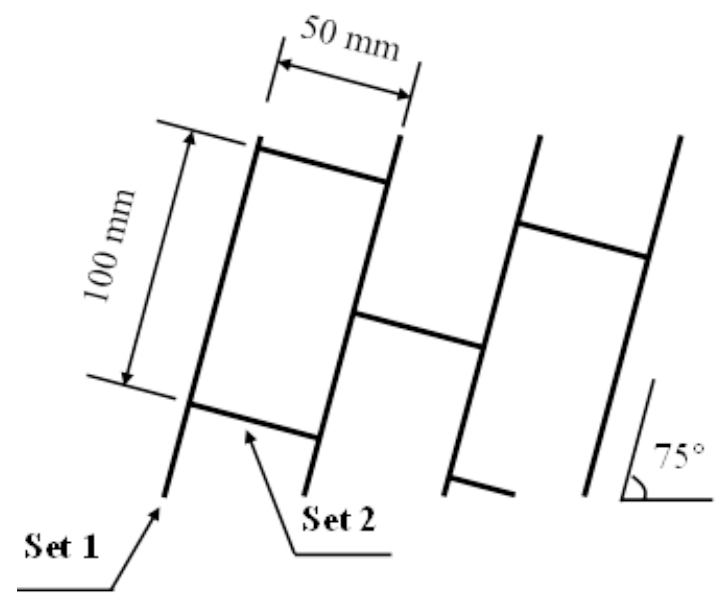

Figure 3. Schematic view of the geometrical distributions of rock joints at location A (a) and location B (b). 


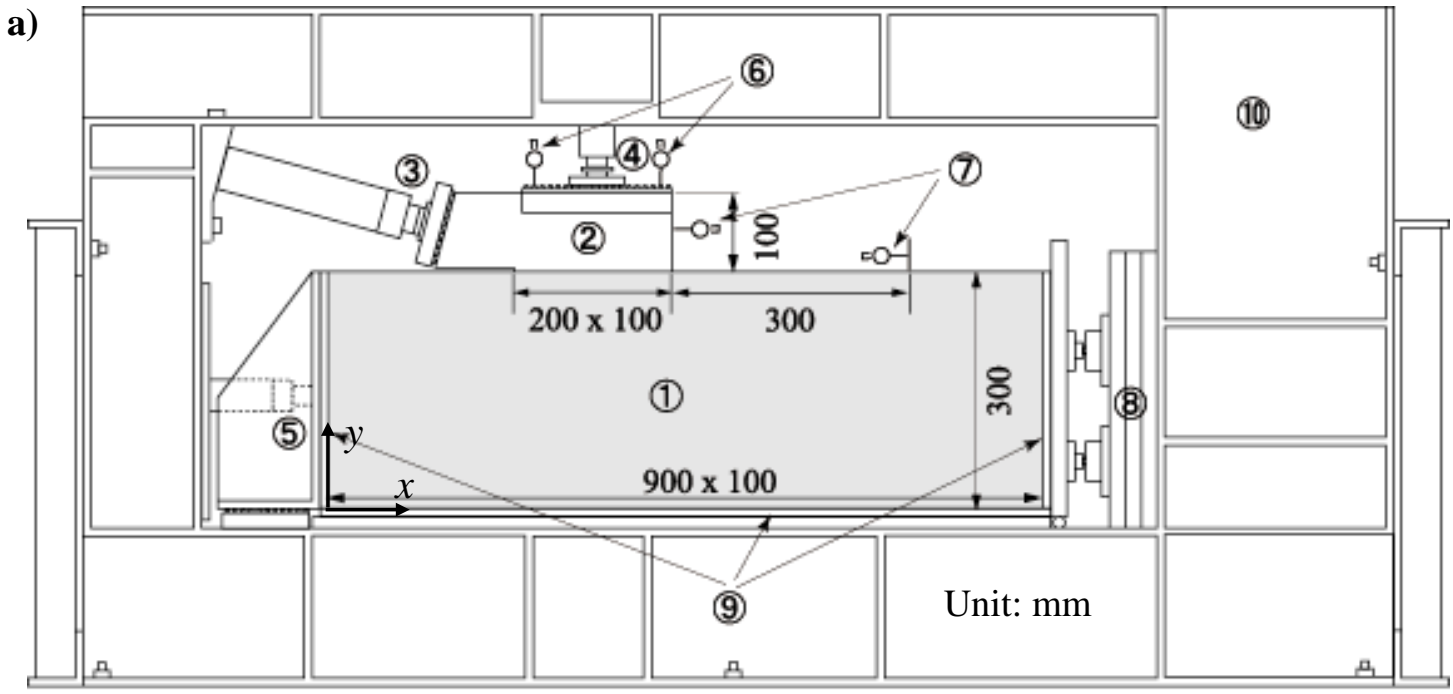

(1): Jointed rock mass model

(5): Lateral restraint jack

(8): Lateral load cell

(2): Loading block

(6): LVDT (normal displacement)

(9): Teflon sheet

(3): Shear load jack

(7): LVDT (shear displacement)

(10): Metal frame

(4): Normal load jack

b)

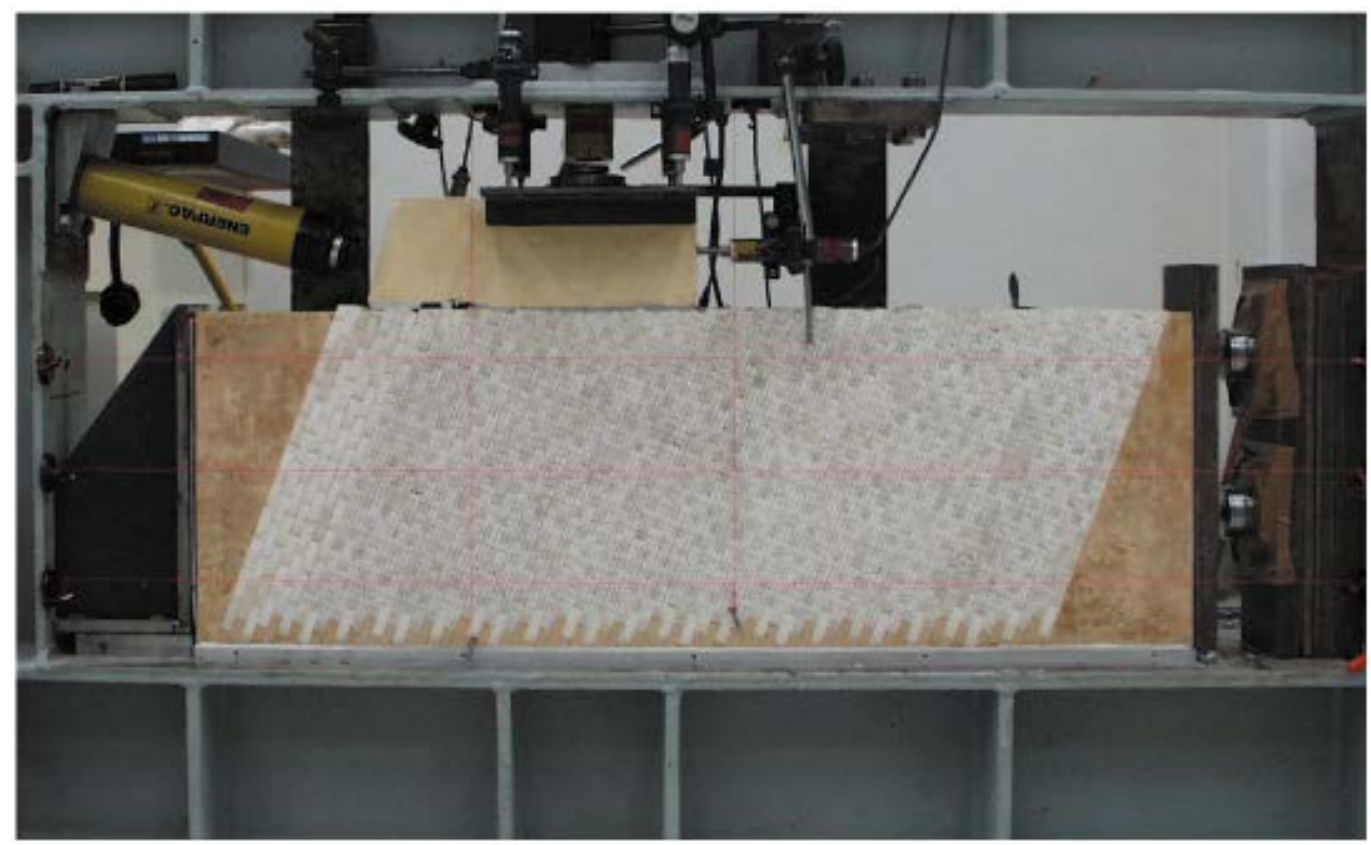

Figure 4. a) Sketch of the direct shear test apparatus designed for jointed rock mass; b) Photograph of jointed rock mass model in the apparatus. 


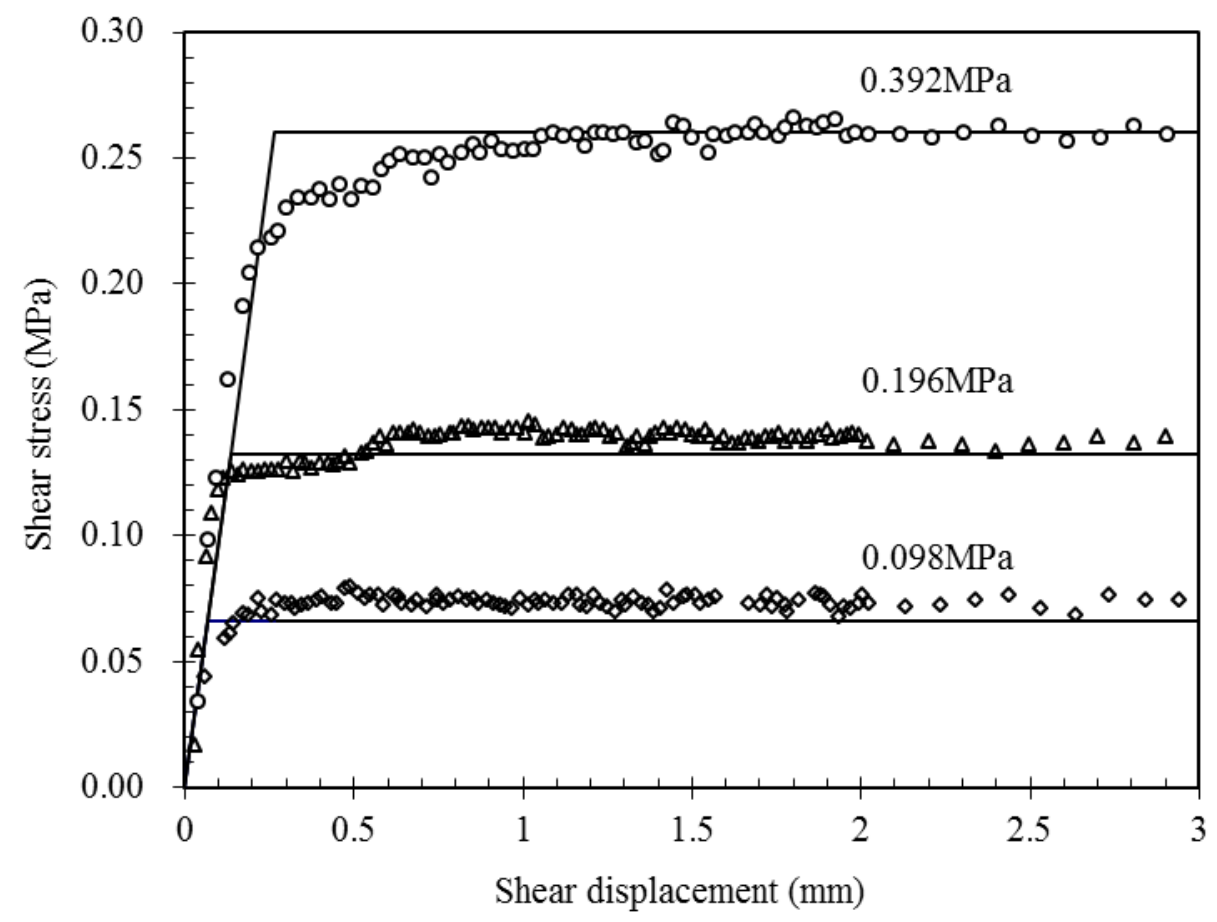

Figure 5. Relationship between shear stress and shear displacement for the artificial rock joints tested under normal stresses of $0.098 \mathrm{MPa}, 0.196 \mathrm{MPa}$ and $0.392 \mathrm{MPa}$. Straight lines represent the approximations for estimating the properties of the shear behavior of the rock joints. 

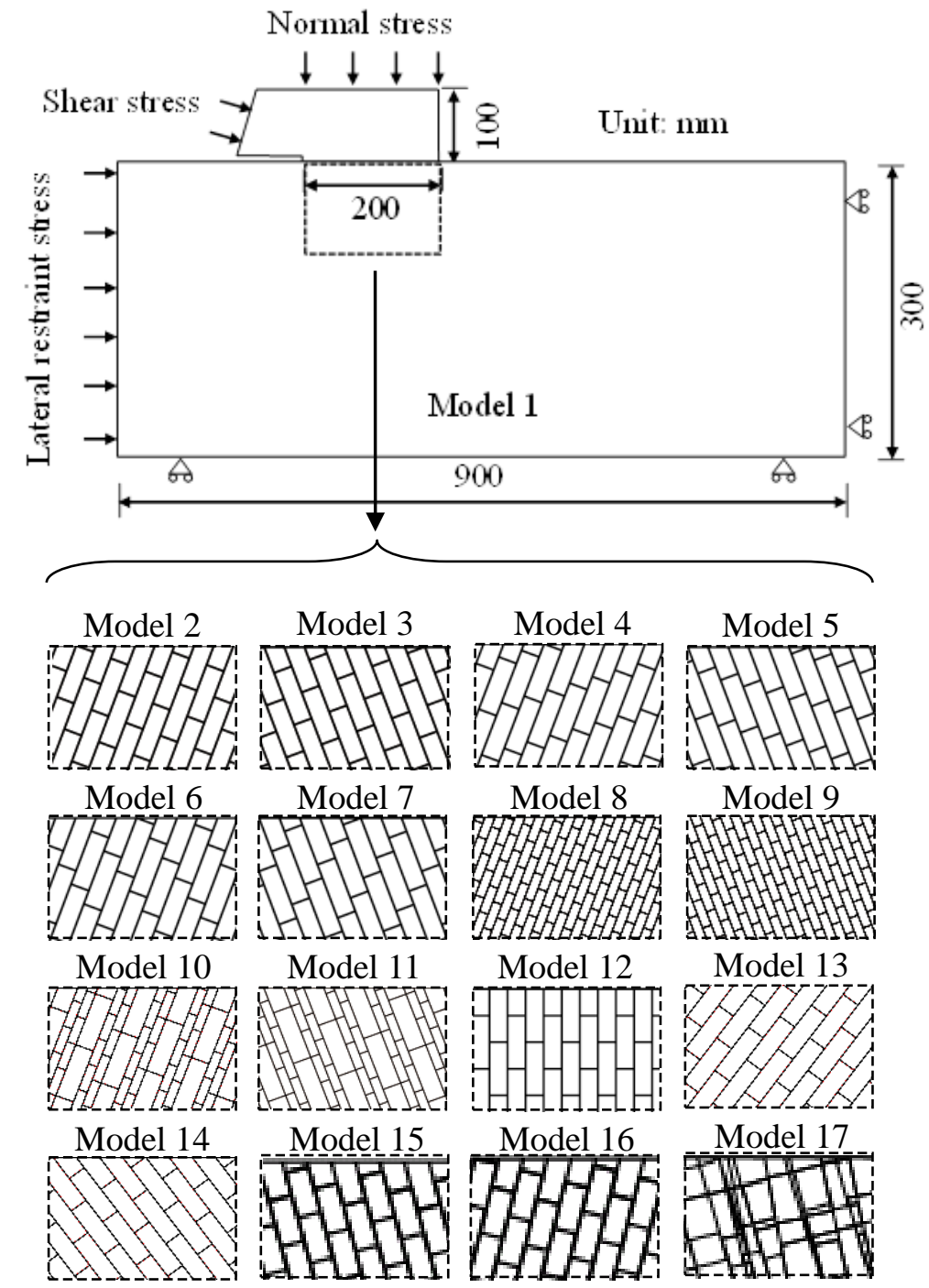

Figure 6. Numerical models for simulating laboratory (Models 1-14) and in-situ shear tests (Models 15-17). Sketches for the models 2-17 show the joint distribution patterns in the area (dash line) underneath the loading block in model 1 . Note that the scale of models 15-17 has been reduced to fit the view. 

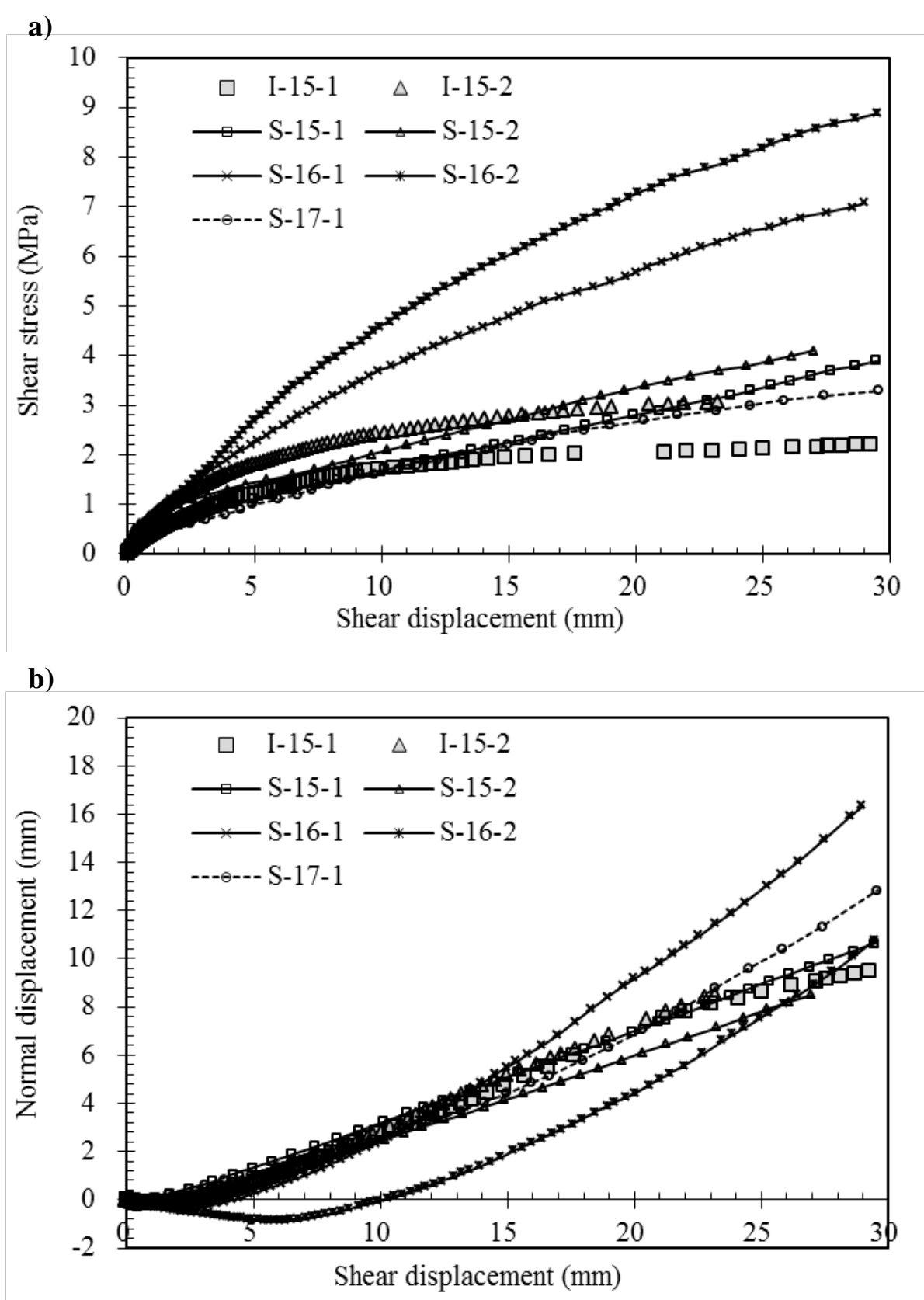

Figure 7. Curves of shear stress-shear displacement (a) and normal displacement-shear displacement (b) of in-situ shear tests and their numerical simulations. 

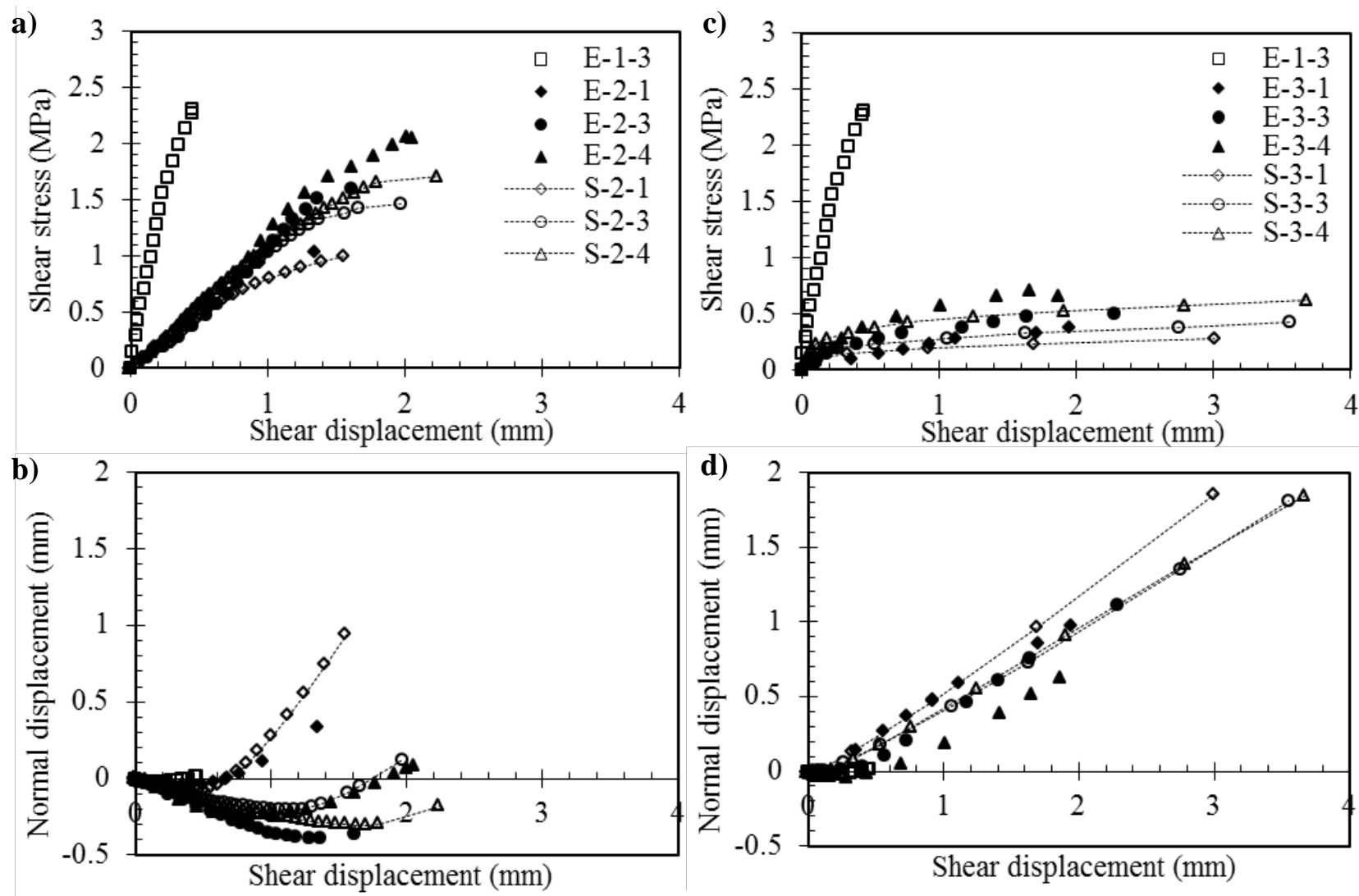

Figure 8. Curves of shear stress-shear displacement (a \& c), and normal displacement-shear displacement (b \& d) of Models 1, 2 \& 3, with the comparisons of experimental and simulation results. 
a) $0.66 \mathrm{MPa}$

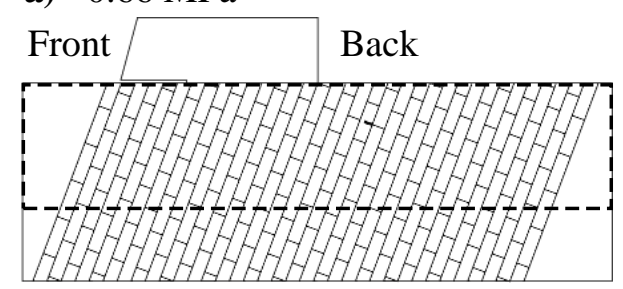

b) $\quad 0.85 \mathrm{MPa}$

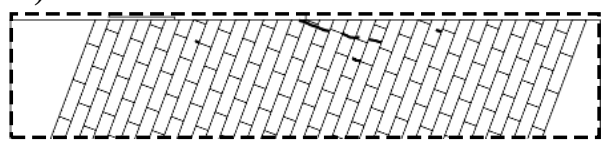

c) $0.95 \mathrm{MPa}$

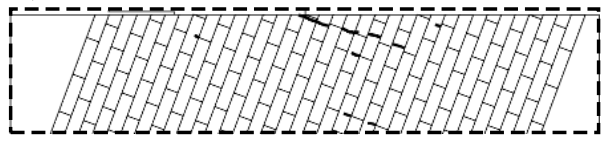

d) $1.03 \mathrm{MPa}$

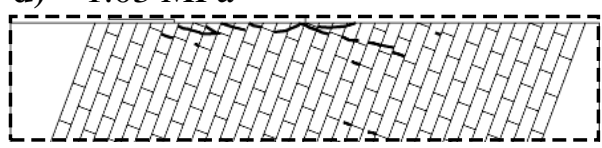

e) $0.28 \mathrm{MPa} \quad$ : new cracks

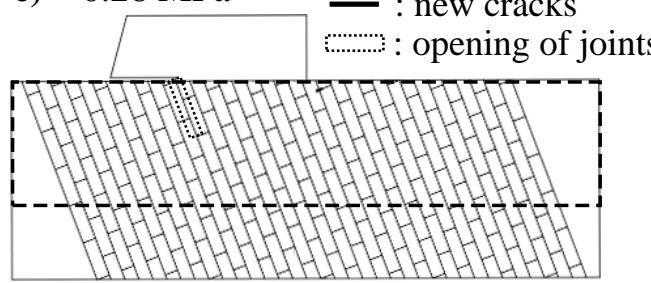

f) $0.33 \mathrm{MPa}$

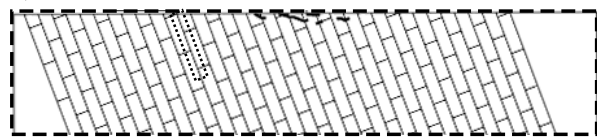

g) $0.38 \mathrm{MPa}$

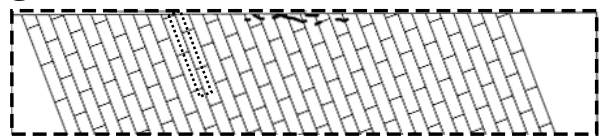

h) $0.41 \mathrm{MPa}$

Figure 9. Cracking processes and opening of joints in the models of cases E-2-1 (left) and E-3-1 (right) with updated shear stresses during shear. For simplicity, the joints with measured apertures larger than $0.1 \mathrm{~mm}$ were judged as “opening”. Except a) \& e), others sketches only show the rectangular part marked in dash line in a) \& e) to save the space, since there are no cracks being generated in the lower part of the models. 


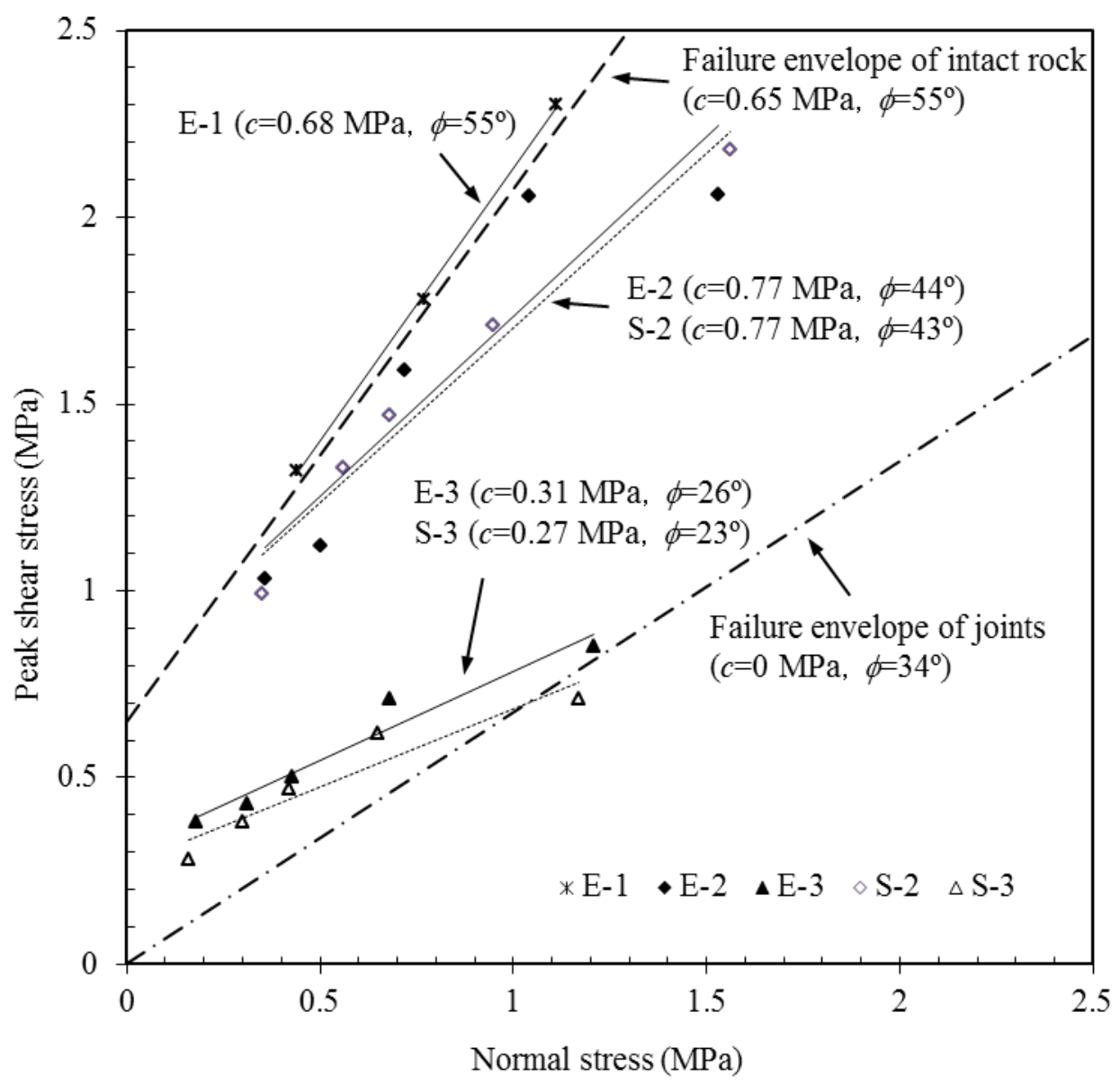

Figure 10. Comparisons of the peak shear stress-normal stress relations of Models 1, $2 \& 3$, their numerical simulation results and the failure envelopes of intact rock and rock joints. Straight fine lines and dash lines are linear approximations of the test and simulation results at failure, respectively. 


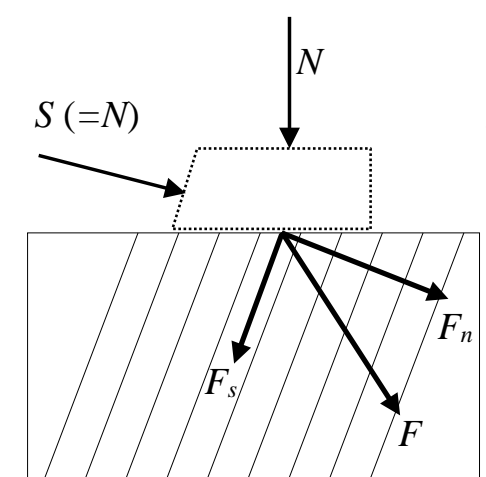

a)

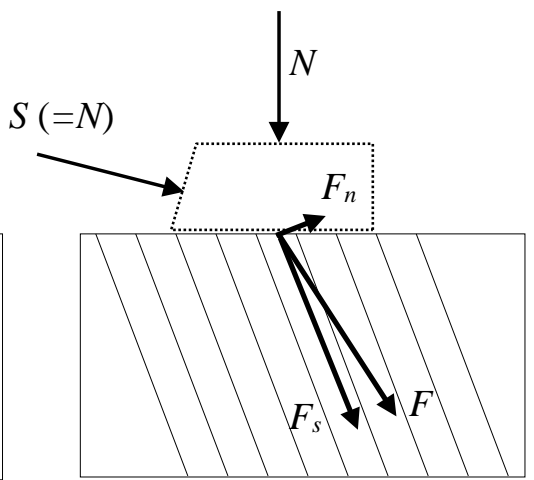

b) Negative dip angle

Figure 11. Schematic view of the forces acting on the continuous joint set in the models with positive (a) or negative (b) dip angles. 

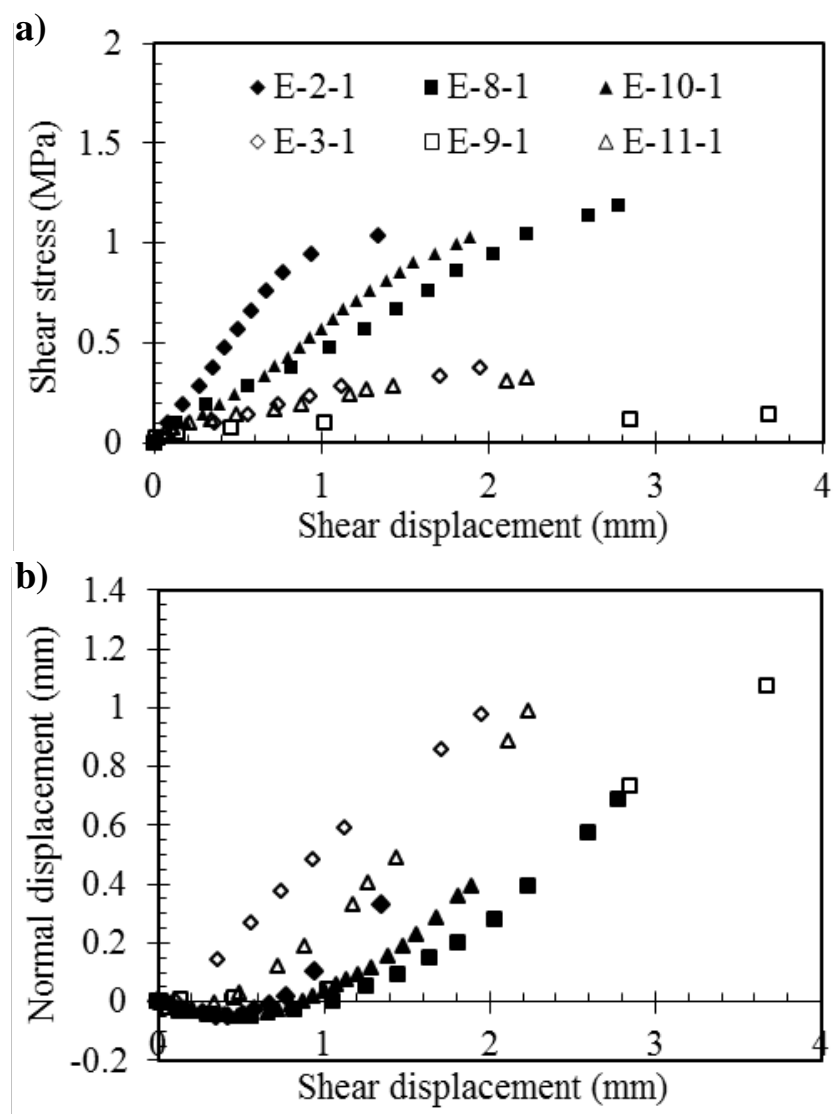

Figure 12. Curves of shear stress-shear displacement (a) and normal displacement-shear displacement (b) of cases E-2-1 \& E-3-1 with rock block dimension of $20 \mathrm{~mm} \times 60 \mathrm{~mm}$, cases E-8-1 \& E-9-1 with rock block dimension of 10 $\mathrm{mm} \times 30 \mathrm{~mm}$ and cases E-10-1 \& E-11-1 with mixed rock block dimensions of both. 

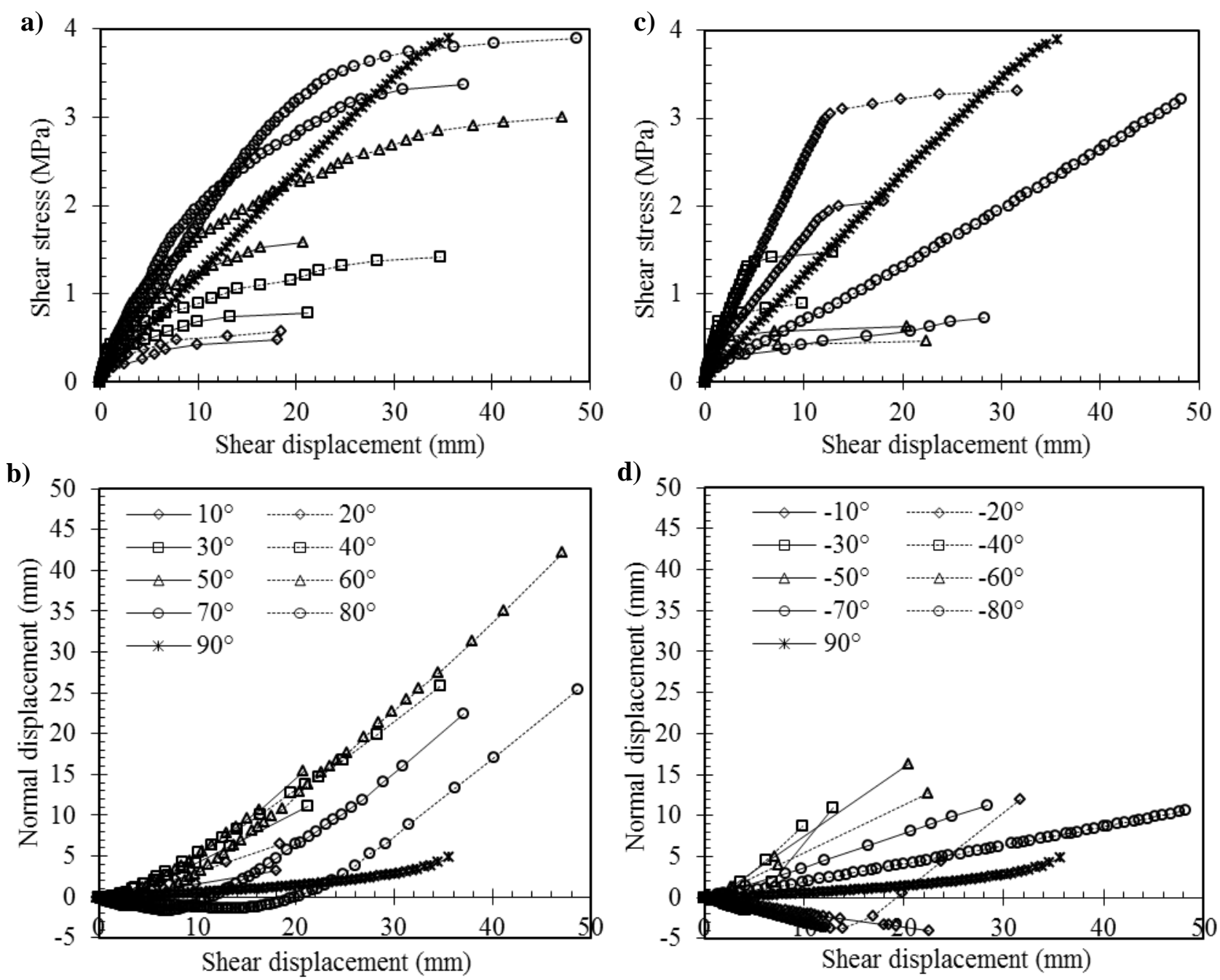

Figure 13. Curves of shear stress-shear displacement and normal displacement-shear displacement of numerical models with positive dip angles (a \& b) and negative dip angles (c \& d), respectively. The initial normal stress is $0.39 \mathrm{MPa}$. 


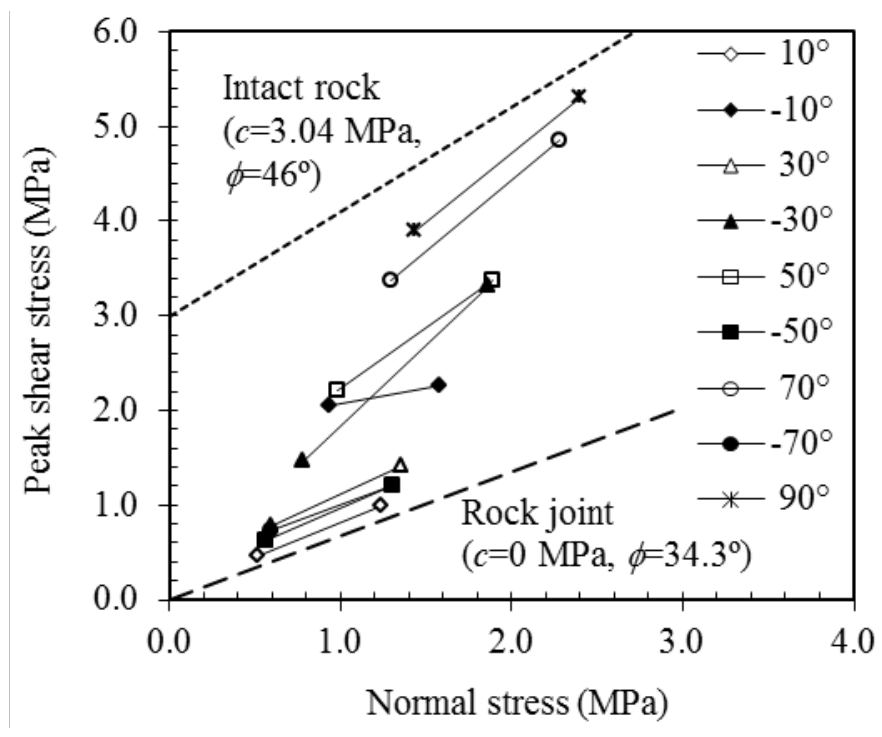

Figure 14. Peak shear stress-normal stress relations of the cases $\theta= \pm 10^{\circ}, \pm 30^{\circ}, \pm 50^{\circ}$, $\pm 70^{\circ} \& 90^{\circ}$, and the strength envelopes of the intact rock and rock joints. 


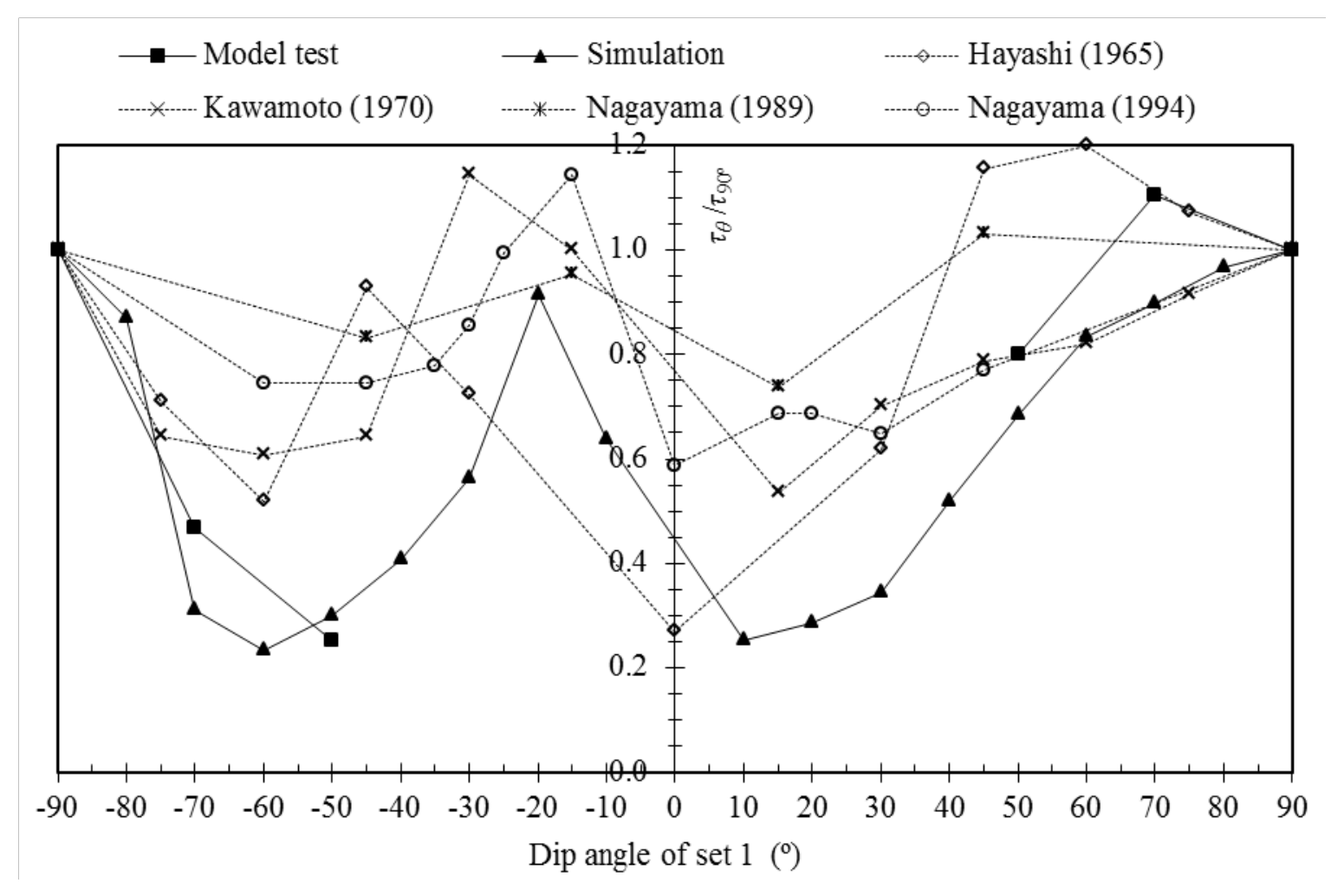

Figure 15. Comparisons of the relations of normalized shear strength $\tau_{\theta} / \tau_{90^{\circ}}$ at various dip angels of the joints of Set 1 , among the model tests and numerical simulations conducted in this study and other laboratory model tests in literature. 
Table 1. Properties of artificial rock specimens adopted in laboratory tests (Lab) and of intact rocks in locations A and B.

\begin{tabular}{llccc}
\hline Property & Unit & Lab & $\mathrm{A}$ & $\mathrm{B}$ \\
\hline Density & $\mathrm{g} / \mathrm{cm}^{3}$ & 1.68 & 2.66 & 2.66 \\
Modulus of elasticity & $\mathrm{GPa}$ & 5.8 & 14.8 & 71.0 \\
Poisson's ratio & - & 0.18 & 0.19 & 0.18 \\
Tensile strength & $\mathrm{MPa}$ & 0.5 & 1.4 & 10.2 \\
Cohesion & $\mathrm{MPa}$ & 0.7 & 3.0 & 22.3 \\
Internal friction angle & $\circ$ & 54.6 & 46.0 & 62.0 \\
\hline
\end{tabular}


Table 2. Mechanical properties of artificial rock joints adopted in laboratory tests (Lab) and of rock joints in locations A and B.

\begin{tabular}{llccc}
\hline Property & Unit & Lab & A & B \\
\hline Normal stiffness & GPa $/ \mathrm{m}$ & Eq. (1) & 18.3 & 31.8 \\
Shear stiffness & GPa /m & 1.0 & 0.9 & 3.2 \\
Cohesion force & MPa & 0 & 0 & 0.03 \\
Friction angle & $\circ$ & 34.0 & 34.3 & 35.9 \\
Tension strength & MPa & 0 & 0 & 0 \\
\hline
\end{tabular}


Table 3. Laboratory shear test and simulation results (at failure) for the jointed rock mass models. (E: Experiment, S: Simulation and $R$ : Correlation coefficient)

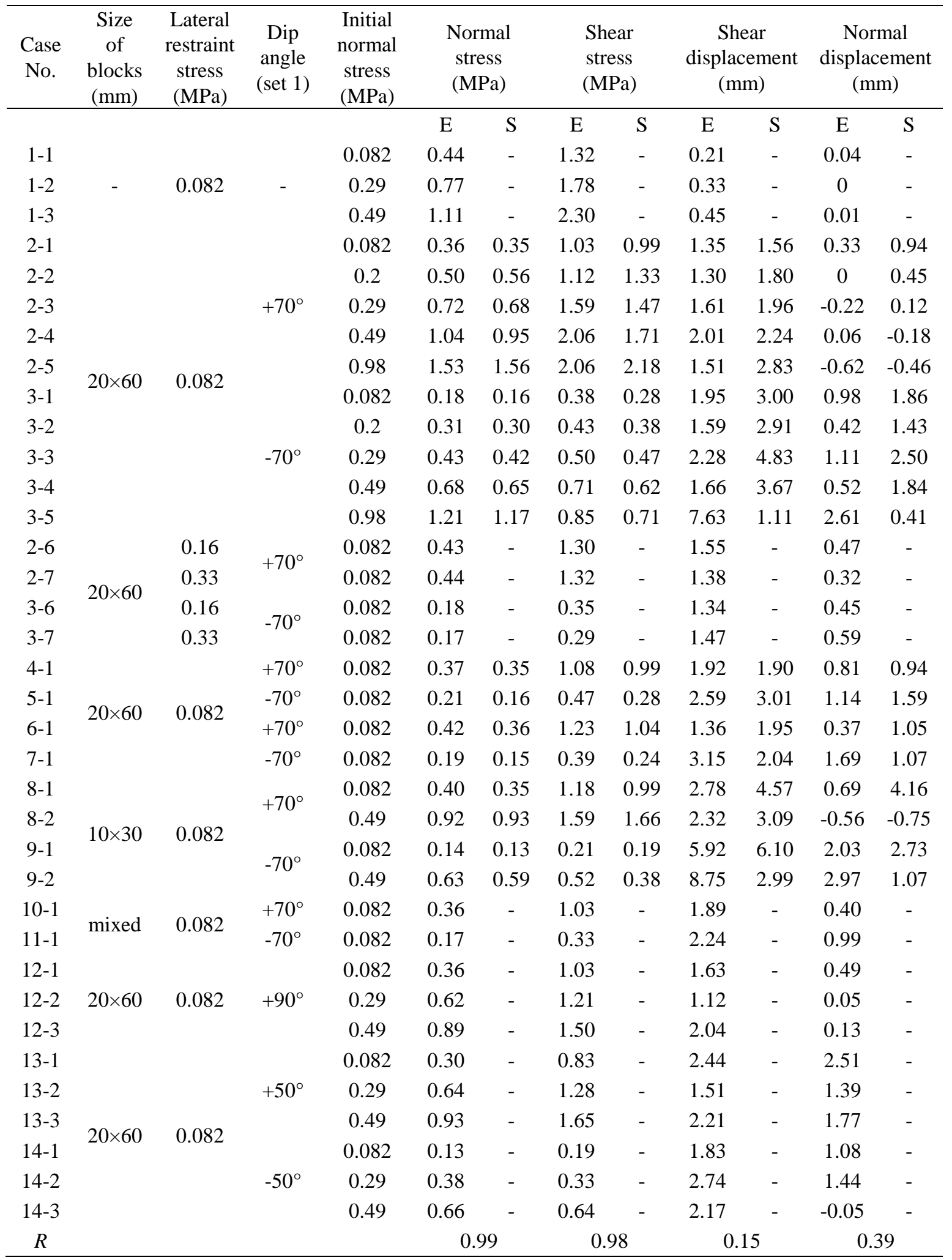


Table 4. Numerical simulation results (at failure) of in-situ shear tests based on the properties of jointed rock mass at location A with various dip angles of continuous joint set.

\begin{tabular}{|c|c|c|c|c|c|}
\hline $\begin{array}{l}\text { Initial normal } \\
\text { stress (MPa) }\end{array}$ & $\begin{array}{l}\text { Dip angle } \\
\text { of Set } 1\left(^{\circ}\right)\end{array}$ & $\begin{array}{c}\text { Normal } \\
\text { stress } \\
(\mathrm{MPa})\end{array}$ & $\begin{array}{l}\text { Shear } \\
\text { stress } \\
(\mathrm{MPa})\end{array}$ & $\begin{array}{l}\text { Shear } \\
\text { disp. } \\
(\mathrm{mm})\end{array}$ & $\begin{array}{c}\text { Normal } \\
\text { disp. } \\
\text { (mm) }\end{array}$ \\
\hline \multirow{17}{*}{0.39} & 10 & 0.52 & 0.47 & 18.15 & 3.25 \\
\hline & 20 & 0.55 & 0.58 & 18.53 & 6.50 \\
\hline & 30 & 0.60 & 0.79 & 21.27 & 11.18 \\
\hline & 40 & 0.77 & 1.42 & 34.70 & 25.85 \\
\hline & 50 & 0.99 & 2.21 & 46.27 & 41.42 \\
\hline & 60 & 1.20 & 3.00 & 47.23 & 42.19 \\
\hline & 70 & 1.26 & 3.37 & 37.09 & 22.47 \\
\hline & 80 & 1.44 & 3.90 & 48.61 & 25.45 \\
\hline & 90 & 1.44 & 3.90 & 35.65 & 4.86 \\
\hline & -80 & 1.25 & 3.21 & 48.25 & 10.61 \\
\hline & -70 & 0.59 & 0.74 & 28.32 & 11.22 \\
\hline & -60 & 0.52 & 0.47 & 22.35 & 12.66 \\
\hline & -50 & 0.56 & 0.63 & 20.40 & 16.34 \\
\hline & -40 & 0.63 & 0.90 & 9.80 & 8.75 \\
\hline & -30 & 0.79 & 1.48 & 12.88 & 10.89 \\
\hline & -20 & 1.28 & 3.32 & 31.67 & 11.90 \\
\hline & -10 & 0.94 & 2.05 & 18.04 & -3.27 \\
\hline \multirow{17}{*}{0.98} & 10 & 1.25 & 1.00 & 33.28 & 6.21 \\
\hline & 20 & 1.29 & 1.16 & 32.79 & 11.19 \\
\hline & 30 & 1.36 & 1.42 & 27.49 & 12.88 \\
\hline & 40 & 1.63 & 2.42 & 46.21 & 30.94 \\
\hline & 50 & 1.88 & 3.37 & 57.68 & 44.77 \\
\hline & 60 & 2.19 & 4.46 & 60.20 & 40.27 \\
\hline & 70 & 2.28 & 4.85 & 53.36 & 23.98 \\
\hline & 80 & 2.52 & 5.74 & 45.91 & 6.13 \\
\hline & 90 & 2.41 & 5.32 & 52.24 & 6.87 \\
\hline & -80 & 2.24 & 4.69 & 67.70 & 13.25 \\
\hline & -70 & 1.31 & 1.21 & 43.66 & 16.45 \\
\hline & -60 & 1.22 & 0.90 & 23.44 & 12.34 \\
\hline & -50 & 1.31 & 1.21 & 10.94 & 6.79 \\
\hline & -40 & 1.49 & 1.90 & 11.31 & 7.17 \\
\hline & -30 & 1.87 & 3.32 & 38.66 & 31.71 \\
\hline & -20 & 2.15 & 4.37 & 39.59 & -12.00 \\
\hline & -10 & 1.59 & 2.27 & 18.42 & -3.48 \\
\hline
\end{tabular}

